\title{
Phosphatidic acid mediates demyelination in Lpin1 mutant mice
}

\author{
Karim Nadra, ${ }^{1}$ Anne-Sophie de Preux Charles, ${ }^{1,2}$ Jean-Jacques Médard, ${ }^{1}$ William T. Hendriks, ${ }^{3}$ \\ Gil-Soo Han, ${ }^{4}$ Sandra Grès, ${ }^{5}$ George M. Carman, ${ }^{4}$ Jean-Sébastien Saulnier-Blache, ${ }^{5}$ \\ Mark H.G. Verheijen, ${ }^{3}$ and Roman Chrast ${ }^{1,6}$

\begin{abstract}
${ }^{1}$ Department of Medical Genetics, University of Lausanne, 1005 Lausanne, Switzerland; ${ }^{2}$ Graduate Program in Neurosciences, University of Lausanne, 1015 Lausanne, Switzerland; ${ }^{3}$ Department of Molecular and Cellular Neurobiology, Center for Neurogenomics and Cognitive Research, VU University Amsterdam, 1081 HV Amsterdam, The Netherlands; ${ }^{4}$ Department of Food Science and Rutgers Center for Lipid Research, Rutgers University, New Brunswick, New Jersey 08901, USA; ${ }^{5}$ INSERM, U858/I2MR, Department of Metabolism and Obesity, BP 84225, 31432 Toulouse Cedex 4, France
\end{abstract}

\begin{abstract}
Lipids play crucial roles in many aspects of glial cell biology, affecting processes ranging from myelin membrane biosynthesis to axo-glial interactions. In order to study the role of lipid metabolism in myelinating glial cells, we specifically deleted in Schwann cells the Lpin1 gene, which encodes the $\mathrm{Mg}^{2+}$-dependent phosphatidate phosphatase (PAP1) enzyme necessary for normal triacylglycerol biosynthesis. The affected animals developed pronounced peripheral neuropathy characterized by myelin degradation, Schwann cell dedifferentiation and proliferation, and a reduction in nerve conduction velocity. The observed demyelination is mediated by endoneurial accumulation of the substrate of the PAP1 enzyme, phosphatidic acid (PA). In addition, we show that PA is a potent activator of the MEK-Erk pathway in Schwann cells, and that this activation is required for PA-induced demyelination. Our results therefore reveal a surprising role for PA in Schwann cell fate determination and provide evidence of a direct link between diseases affecting lipid metabolism and abnormal Schwann cell function.
\end{abstract}

[Keywords: Schwann cells; myelin; peripheral neuropathy; lipid metabolism; phosphatidic acid]

Supplemental material is available at http://www.genesdev.org.

Received November 29, 2007; revised version accepted April 18, 2008.

Myelinating glial cells are vital for normal function of the neural system. Both oligodendrocytes in the central neural system (CNS) and Schwann cells (SC) in the peripheral neural system (PNS) produce myelin necessary for the insulation of axons allowing for faster saltatory propagation of action potentials, provide trophic support for underlying axons, and play a crucial role in axonal guidance and regeneration. Disruption of any of these functions by diseases, such as metabolic disorders, infections, immune-mediated inflammatory disorders, or inherited forms of neuropathy, is invariably and severely debilitating (Dyck and Thomas 2005).

Lipid metabolism is thought to be crucial for myelinating glial cell maturation and function. This is mostly due to the necessity to synthesize and maintain myelin membrane that contains a high level $170 \%-80 \%$ of dry mass) of cholesterol and phospho- and glycosphingolipids (Garbay et al. 2000). Previous studies suggest that the majority of cholesterol is locally synthesized both in the CNS and PNS (Jurevics and Morell 1994; Morell and Ju-

${ }^{6}$ Corresponding author.

E-MAIL roman.chrast@unil.ch; FAX 41-21-6925455.

Article is online at http://www.genesdev.org/cgi/doi/10.1101/gad.1638008. revics 1996). Disruption of squalene synthase in oligodendrocytes, which prevents synthesis of cholesterol in these cells, leads to delayed CNS myelination leading to ataxia and tremor. However, mutant oligodendrocytes survive and overcome dysmyelination by cholesterol uptake (Saher et al. 2005). The origin and exact role of different glial cell lipids remain less well understood. Galactosylceramide (Gal-C) and its sulfated form, sulfatide (SGal-C), are two galactolipids over-represented in myelin membrane. The inactivation of UDP-galactose: ceramide galactosyltransferase (CGT) leads to complete disruption of both Gal-C and SGal-C synthesis. Even though the overall structure of myelin in $C G T^{-/-}$mice appears normal, the knockout animals present defective paranodal axo-glial interactions, leading to tremor, hind limb paralysis, and mortality at $\sim 3$ mo of age (Marcus and Popko 2002).

Using transcriptional analysis of developing sciatic nerve, we previously discovered a large group of genes involved in cholesterol and lipid metabolism that show dynamic changes in the level of their expression during peripheral nerve maturation (Verheijen et al. 2003). We subsequently demonstrated that while some of these genes are expressed only in the adipocytes that populate 
the epineurium of the mature peripheral nerve, the majority of them, including Lpin1, Srebp-1c, and Srebp-2, are also expressed in the endoneurium (Verheijen et al. 2003; de Preux et al. 2007). Lipin 1 protein is the product of the Lpin1 gene, which is mutated in fatty liver dystrophy (Lpin $1^{\text {fld } / f l d}$ ) mice (Peterfy et al. 2001). These mice are characterized by a neonatal fatty liver that resolves at weaning, a progressive demyelinating neuropathy affecting peripheral nerves and lipoatrophy (Langner et al. 1991). The overexpression of lipin 1 in either adipose tissue or skeletal muscle promotes obesity (Phan and Reue 2005). Alternative splicing generates two lipin 1 isoforms that play distinct roles in adipocyte development: lipin $1 \alpha$, which is predominantly nuclear, is required for adipocyte differentiation, while lipin $1 \beta$, which is mostly present in cytoplasm, induces the expression of lipogenic genes (Peterfy et al. 2005). Recent biochemical characterization of lipin 1 indicates that it is a $\mathrm{Mg}^{2+}$-dependent phosphatidate phosphatase (PAP1) enzyme catalyzing the dephosphorylation of phosphatidic acid, yielding inorganic phosphate and diacylglycerol needed for the synthesis of phospholipids and triacylglycerol (Han et al. 2006; Donkor et al. 2007). Lipin 1 localization and activity can be regulated by its phosphorylation (Huffman et al. 2002; O'Hara et al. 2006; Harris et al. 2007).

Our previous results demonstrated that the lipodystrophy in adult Lpin1 mutants extends to the epineurium of the sciatic nerve. Staining of storage lipids in the sciatic nerve highlights the presence of large fat pads in the epineurium of wild-type nerves, while these fat pads are severely reduced in the Lpin1 mutants (Verheijen et al. 2003). These observations raised the question of whether the endoneurial phenotype observed in Lpin $1^{\text {fld flfd }}$ animals (Langner et al. 1991; Verheijen et al. 2003) originates from systemic or Schwann cell autonomous deficit in lipin 1 function. We therefore used the Cre-loxP system to selectively inactivate lipin 1 function in Schwann cells (SC). The conditional knockout animals developed SC abnormalities similar to the complete Lpin1 knockout animals (Lpin $\left.1^{\text {fld } l \text { fld }}\right)$, proving that the neuropathy in these mice is a direct consequence of the absence of lipin 1 -and the subsequent dys-regulation of storage lipid metabolism-within the nerve itself. In addition, these results unveil a complex signaling network in which one of the precursors of triacylglycerol biosynthesis, phosphatidic acid (PA), interacts with the MEK-Erk pathway to mediate Schwann cell dedifferentiation and proliferation.

\section{Results}

Lipin 1 function is not essential for early Schwann cell development but is critical for myelin formation and maintenance

Earlier analysis of Lpin $1^{\text {fld/fld }}$ mice indicates that lipin 1 plays a key role in the peripheral nerve development (Langner et al. 1991; Verheijen et al. 2003). However, the onset and the nature of molecular alterations underlying the changes in myelin structure observed in Lpin1 $1^{\text {fld flld }}$ mice remain mostly unknown. Therefore, we examined the morphology of mutant and control sciatic nerves at postnatal days 4 (P4), 10 (P10), and 56 (P56), by electron microscopy (Fig. 1A). At P4, most of the large caliber axons in both control and mutant nerves reached the proper 1:1 relationship with SCs that started to myelinate them, indicating that the early Schwann cell development is not affected in Lpin1 $1^{\text {fld/fld }}$ mice. By P10, the process of myelination was well advanced in the control animals; however, the delay in myelination could already easily be detected in sciatic nerves isolated from Lpin $1^{\text {fld flfld }}$ mice. At P56, no normally myelinated axons were observed in Lpin $1^{\text {fld flld }}$ nerve. The g-ratio measurement confirmed the presence of hypomyelination in mutant nerves at P10 (Supplemental Fig. 1).

In order to quantitate the myelination defects in Lpin $1^{\text {fld } f \text { fld }}$ mice at the molecular level, we examined the expression of genes involved in myelination at $\mathrm{P0}, \mathrm{P} 4$, P10, and P56 (Fig. 1B). As measured by the expression of Scip/Oct-6 (expressed by "promyelinating" SCs) (Zorick et al. 1996) and two myelin protein-coding mRNAs, $M p z$ and Pmp22, the myelination is initiated correctly /developmental stages PO and P4) in the Lpin1 $1^{\text {fld flfld }}$ nerves. However, starting from P10, the level of expression of myelin genes dramatically decreases compared to controls and is then followed by an increase in the level of Scip expression, indicating a decrease in myelin synthesis and the presence of immature SCs in the mutant nerve (Fig. 1B). Lipin 1 function is therefore not critical for SC development or the initiation of myelination (P0P4) but for normal progression of myelination and myelin maintenance (P10-P56).

\section{Lipin $1 \beta$ is the predominant isoform expressed in peripheral nerve endoneurium}

Lpin1 mRNA undergoes alternative splicing, generating two isoforms, lipin $1 \alpha$ and lipin $1 \beta$, which exhibit differences in expression, subcellular localization (lipin $1 \alpha$ is a nuclear and lipin $1 \beta$ is a predominantly cytoplasmic protein) and cellular function during adipogenesis (Peterfy et al. 2001, 2005). To determine whether the alternative splicing of Lpin1 occurs also during peripheral nerve development, we analyzed by RT-PCR mRNA samples from mouse sciatic nerve at P0, P4, P10, and P56, using primers amplifying both $L p i n 1 \alpha$ and $L p i n 1 \beta$. As demonstrated previously (Verheijen et al. 2003), overall Lpin1 expression increased significantly during sciatic nerve development (Fig. 2a). The expression of Lpin1 in immature or non-myelinating Schwann cells (at P0 and in mouse Schwann cell line 80; MSC 80) showed a one-toone ratio between the $\alpha$ - and $\beta$-type isoforms. Starting from $P 4, L$ pin $1 \beta$ was the predominant splice variant detected with gradual increase in its expression at P10 and P56. In contrast, $L p i n 1 \alpha$ expression remained at a very low level throughout all assessed developmental stages (Fig. 2a; Supplemental Fig. 2a). The expression of two other Lpin family members (Lpin2 and Lpin3) was not detected (Supplemental Fig. 2b). Western blot analysis of the endoneurial protein extract, using the lipin $1 \beta$-spe- 
A

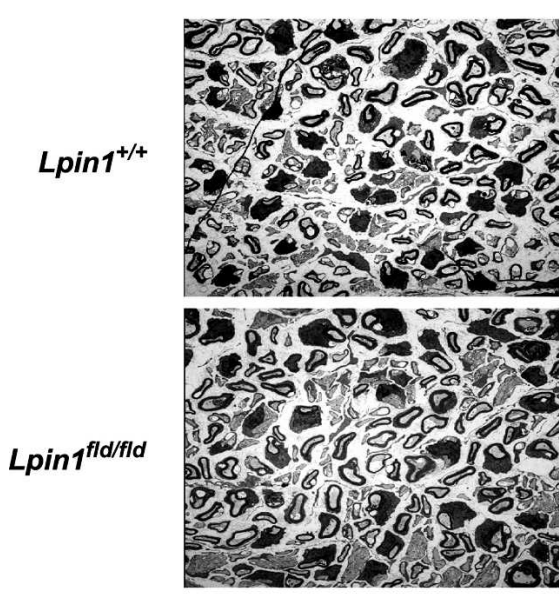

B

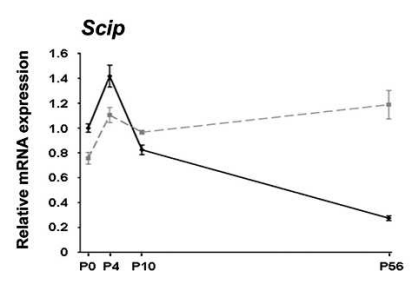

P10

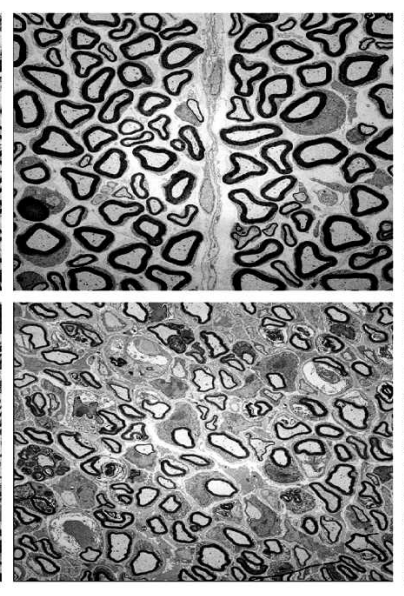

P56

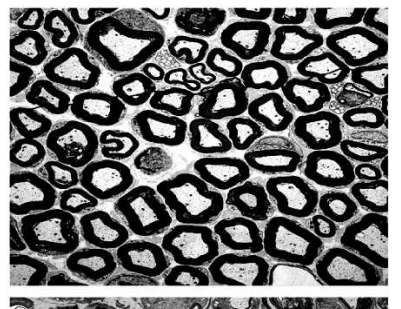

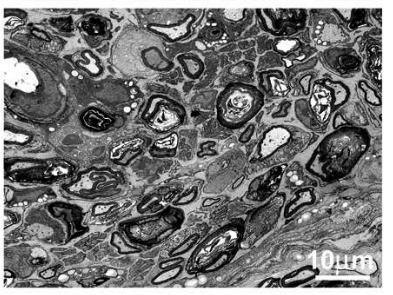
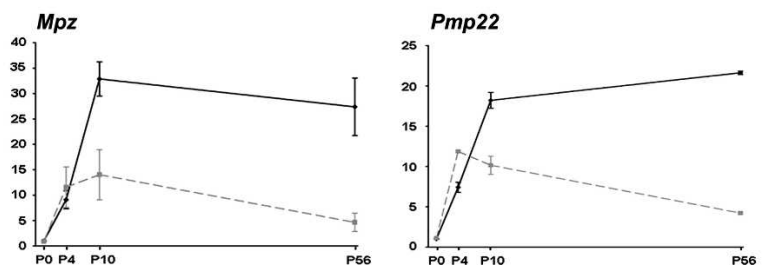

Figure 1. Lipin 1 inactivation leads to a defect in myelin synthesis and maintenance. $(A)$ Electron micrographs of sciatic nerves isolated from wild-type $\left(\operatorname{Lpin} 1^{+/+}\right)$or mutant mice $\left(\operatorname{Lpin} 1^{f l d / f l d}\right)$ at P4, P10, and P56. While at P4 the level of myelination is comparable in wild-type and mutant nerve, the hypomyelination is visible at P10 and demyelination becomes obvious at P56. (B) Quantitative PCR measurements of the level of myelin gene mRNA expression. Relative levels of Scip, Mpz, and Pmp22 were determined in whole sciatic nerves at P0, P4, and P10 and in sciatic nerve endoneurium at P56 isolated from wild type (full black line) and Lpin $1^{\text {fld } / f l d}$ (dotted gray line) animals. For each time point, the mRNA levels are represented as fold increase over the mRNA expression level at P0. The data represent the mean $\pm \mathrm{SD}$ of triplicate measurements.

cific antibody that we developed, confirmed the expression of the $\beta$-isoform in sciatic nerve (Fig. $2 b$ ). Immunohistochemical analysis showed that lipin $1 \beta$ is expressed both in peri/epineurium and endoneurium of sciatic nerve (Fig. 2c,d). Importantly, co-labeling with myelin marker MBP clearly demonstrated the expression of lipin $1 \beta$ by myelinating Schwann cells (Fig. 2e,f).

\section{Inactivation of the Lpin1 gene in Schwann cells}

White adipose tissue, liver, and peripheral nerves are affected in $\operatorname{Lpin} 1^{\text {fld flld }}$ mice. This, together with relatively unrestricted expression of lpin 1 in wild-type mice (Fig. 2c; Donkor et al. 2007), leaves open the question of whether the phenotype observed in the PNS in mutant mice is due to the cell-autonomous defect in lipin 1 function in Schwann cells, or is an indirect consequence of its missing function in adjacent tissues (e.g., adipocytes present in the epineurial compartment of the peripheral nerve) (Verheijen et al. 2003). As the start codon of the Lpin 1 gene is in exon 2, and as exon 3 contains the sequence mutated in Lpin $1^{\text {fld } 2 i / f l d 2 j}$ mice (Gly84Arg substitution), which leads to the identical phenotype as observed in Lpin $1^{\text {fld/fld }}$ mice (Peterfy et al. 2001), we generated mice in which loxP sites flank the second and third Lpin1 exons (Fig. 3A-C). Mice homozygous for the targeted allele $\left(\right.$ Lpin $\left.1^{f E 2-3 / f E 2-3}\right)$ developed normally, indicating that the presence of the neo ${ }^{\mathrm{R}}$ gene and the loxP sites does not affect normal lipin 1 function. In order to inactivate Lpin1 selectively in myelinating Schwann cells, we crossed the Lpin $1^{f E 2-3 / f E 2-3}$ mice with mice expressing Cre recombinase specifically in Schwann cells under the control of the myelin protein zero promoter $\left[\mathrm{mP}_{\mathrm{O}} \mathrm{TOTA}(\mathrm{Cre})\right]$ (Feltri et al. 1999). Generated $\mathrm{MPZ}^{+/+} /$ $L p^{f E 2-3 / f E 2-3}$ mice did not show any detectable level of exon 2-3 recombination. However, in the Cre-expressing animals $\left(M P Z^{\text {cre/+}} / L p^{f E 2-3 / f E 2-3}\right)$, we detected a significant level of exon 2-3 deletion specifically in the endoneurium of sciatic nerve (Fig. 3D), leading to a substantial decrease in lipin 1 expression at the mRNA and protein levels (Fig. 3E,F). The detectable residual lipin 1 expression in the endoneurium of the conditional mice (Fig. 3E,F; Supplemental Fig. 3) may come from the presence of fibroblasts, endothelial cells, or macrophages that are not directly affected by the conditional Lpin1 inactivation.

\section{Schwann cell-specific Lpin1 knockout mice develop a severe neuropathy}

$M P Z^{C r e /+} / L p^{f E 2-3 / f E 2-3}$ mice developed a progressive peripheral neuropathy that becomes manifest by an abnor- 


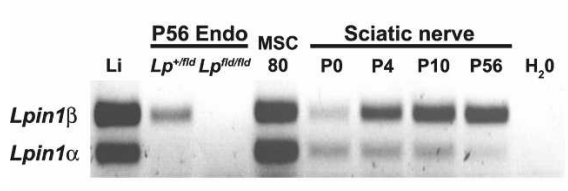

Figure 2. Lipin 1 expression in the endoneurium of sciatic nerve. (a) Equal amounts of cDNA derived from wild-type sciatic nerve at P0, P4, P10, and P56; from control $\left(L p^{+/ f l d}\right)$ and Lpin1 $1^{\text {fld/fld }}\left(L p^{\text {fld/fld }}\right)$ endoneurium at P56 (P56 Endo); wild-type liver at P56 (Li); and mouse Schwann cell line MSC80 were analyzed by RT-PCR using primers amplifying both $L$ pin $1 \alpha$ and $\beta$ isoforms. Starting from $\mathrm{P} 4, L$ pin $1 \beta$ is the major isoform expressed in the nerve. $(b)$ Western blots showing the expression of the lipin $1 \beta$ isoform in endoneurium fractions of wild-type $\left(L p^{+/+}\right)$and Lpin $1^{\text {fld/fld }}\left(L p^{f l d / f l d}\right)$ adult sciatic nerve. Western blotting was done against tubulin to determine equal protein loading. (WAT) White adipose tissue; (Endo) endoneurium. (c) Immunolabeling of lipin $1 \beta$ (red), myelin basic protein (MBP, green), and DAPI (blue) shows the expression of lipin $1 \beta$ protein both in endoneurium and peri/epineurium of wild-type adult (P56) mouse sciatic nerve. (d) This labeling is lost in Lpin $1^{\text {fld } / \text { fld }}$ nerve. High magnification of the endoneurial part of the nerve shows the expression of lipin $1 \beta$ by myelinating Schwann cells (red-stained croissantshaped cells pointed to by white arrowheads) localized near myelin rings (green) in wild-type nerve $(e)$ and its absence in Lpin $1^{\text {fld } l \text { fld }}$ nerve $(f) .(d, f)$ Note the increased number of nuclei in endoneurium of Lpin1 $1^{\text {fld flfld }}$ mice reflecting aberrant Schwann cell proliferation. a

b
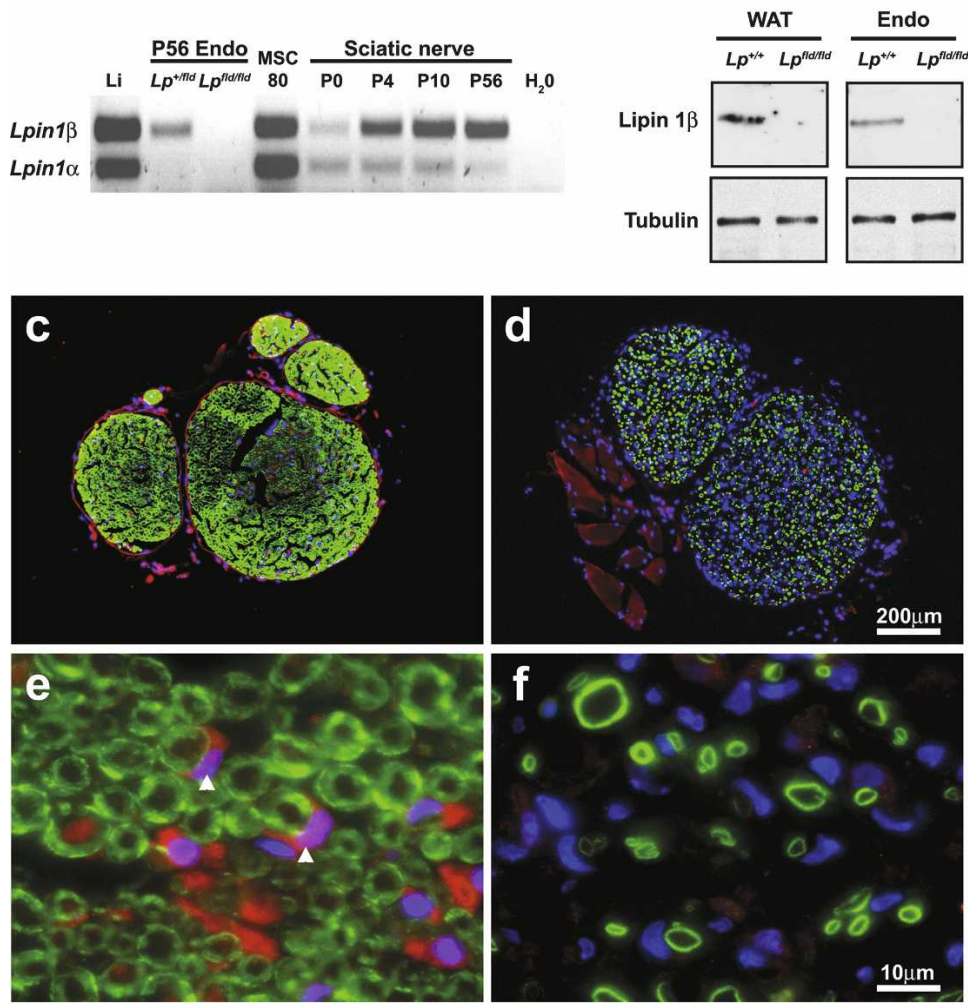

mal gait at the end of the second postnatal week and persists through adulthood. Similar to Lpin $1^{\text {fld/fld }}$ mice, the mutant animals could also be identified by their clenching of the toes of their rear feet when held up by their tail (Fig. 4A,C). Electrophysiological evaluation of sciatic nerve function revealed a strong reduction in motor nerve conduction velocity (MNCV) in the $L p i n 1^{\text {fld } / f l d}$ and $M P Z^{C r e /+} / L p^{f E 2-3 / f E 2-3}$ mice $(5 \pm 1.3$ and $8.8 \pm 2.6$ $\mathrm{m} / \mathrm{sec}$, respectively) as compared with age-matched control mice $(42 \pm 3.8$ and $40.5 \pm 2.9 \mathrm{~m} / \mathrm{sec}$, respectively) (Fig. 4B,D). The decrease in MNCV was accompanied by temporal dispersion and a reduction of compound muscle action potentials (data not shown). We next examined the general morphology of mutant (both Lpin $1^{\text {fld/fld }}$ and $\left.M P Z^{\text {Cre/+ }} / L p^{\text {fE2-3/fE2-3 }}\right)$ and control sciatic nerves at P56, using the Oil-red-O staining (Fig. 4E). As previously demonstrated, the number of adipocytes present in the epineurium of Lpin $1^{\text {fld } / f l d}$ mice was dramatically reduced (Verheijen et al. 2003). Surprisingly, the cross-section through the nerve revealed massive accumulation of lipid-containing droplets in the perineurial and endoneurial compartments of the affected nerve. In the $M P Z^{C r e /+} / L p^{f E 2-3 / f E 2-3}$ mice, the epineurial adipocytes did not show any change compared to the wildtype controls. However, the accumulation of lipid-containing particles in the perineurial and endoneurial compartments was still observed. The ultrastructural changes in myelination in the $M P Z^{C r e /+} / L p^{f E 2-3 / f E 2-3}$ mice were evaluated by electron microscopy. At the age of $2 \mathrm{mo}$, all large axons were well myelinated in normal nerves (Fig. 5A). In contrast, sciatic nerves from
$M P Z^{C r e /+} / L p^{f E 2-3 / f E 2-3}$ mutant mice showed strong demyelination similar to $L p i n 1^{\text {fld/fld }}$ nerves (Fig. 5A), accumulation of myelin debris in the SC cytoplasm, increased presence of mast cells, and defects in the unmyelinated Schwann cells. In agreement with the histologically detected demyelination, qPCR demonstrated down-regulation of the level of myelin gene expression $(\mathrm{Mpz}$ and Pmp22), up-regulation in the expression of immature SC markers (Scip, Krox-24, and Cyclin D1), and up-regulation of Apoe (involved in lipid transport) in sciatic nerves isolated from $M P Z^{C r e /+} / L p^{f E 2-3 / f E 2-3}$ mice similar to the changes observed in Lpin $1^{\text {fld } / \text { fld }}$ nerves (Fig. 5B). Using immunohistochemical analysis, we observed up-regulation of immature SC marker, Scip, accompanied by a decreased expression of a key regulator of myelin gene expression, Krox20, and an increase in cell proliferation (BrdU), apoptosis (TUNEL), and macrophage infiltration (F4/80) (Supplemental Fig. 4). Together, these observations demonstrate that the loss of lipin 1 function leads to accumulation of SCs at the pro-myelinating stage in the adult nerve that is associated with increased SC proliferation, apoptosis, and an elevated amount of endoneurial macrophages.

\section{Lipin 1 deficiency leads to the reduction of PAP1 activity and to the consecutive accumulation of PA in endoneurium of peripheral nerve}

The recent biochemical characterization of recombinant lipin 1 has indicated its function as a $\mathrm{Mg}^{2+}$-dependent phosphatidate phosphatase enzyme (PAP1) converting 
A

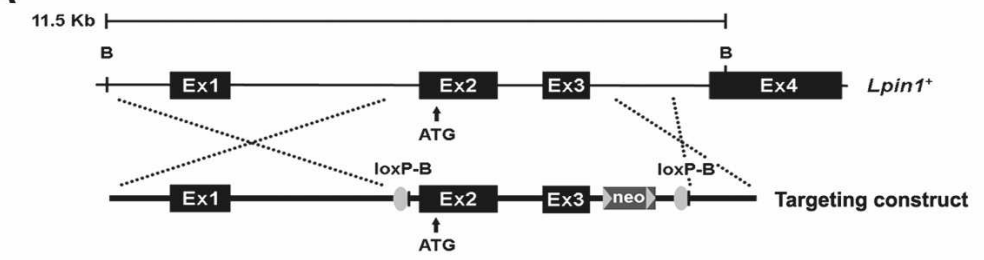

B

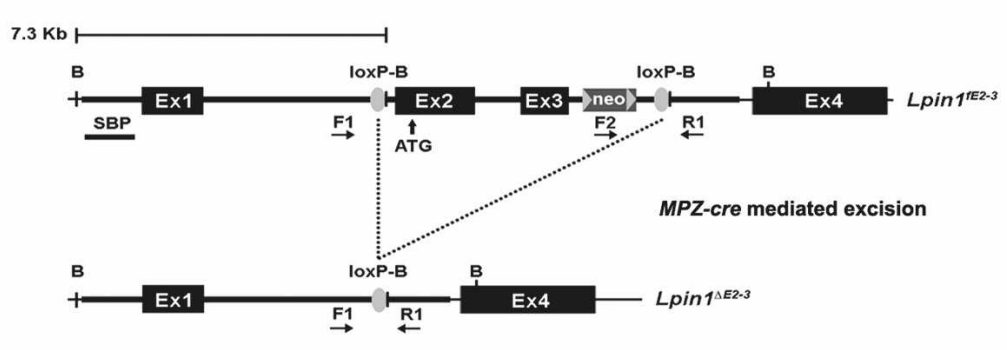

C

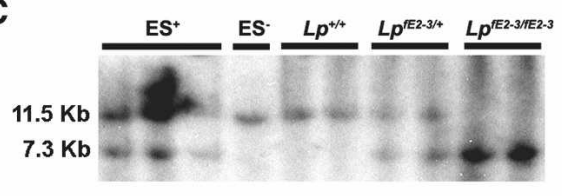

D

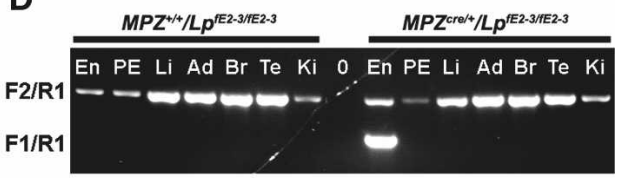

E

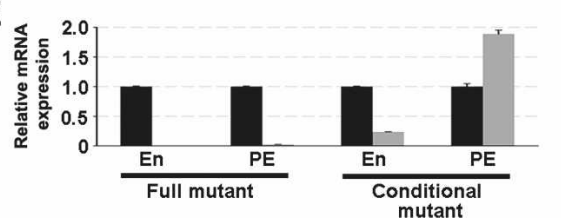

$\mathbf{F}$

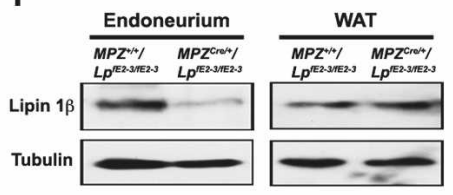

Figure 3. Conditional inactivation of Lpin 1 in Schwann cells. $(A)$ Schematic representation of the Lpin1 wild-type locus $\left(\operatorname{Lpin} 1^{+}\right)$and of the targeting construct. The two loxP sites (loxP-B, gray circle) were inserted into the Lpin1 gene to flank exons 2 and 3. The neomycin resistance gene (neo) was flanked by two FRT (FLP recombinase target) sites (gray triangles). Restriction endonuclease sites used for Southern blot analysis are indicated (B, BamHI). The vertical arrow indicates the position of the translation start site (ATG).

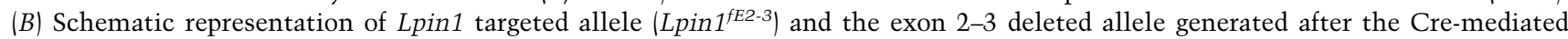
recombination $\left(\operatorname{Lpin} 1^{\triangle E 2-3}\right)$. The position of the $5^{\prime}$ Southern blot probe (SBP) is shown. Horizontal arrows indicate the positions of the primers (F1, F2, and R1) used for PCR amplifications $(D)$. $(C)$ Southern blot analysis of BamHI-digested genomic DNA isolated from mouse embryonic stem cells positive $\left(\mathrm{ES}^{+}\right)$or negative $\left(\mathrm{ES}^{-}\right)$for the targeting construct and from tails of wild-type $\left(L p^{+/+}\right)$, heterozygous $\left(L p^{f E 2-3 /+}\right)$, and homozygous $\left(L p^{f E 2-3 / f E 2-3}\right)$ mice was hybridized with the $5^{\prime}$ probe. $(D)$ PCR analysis of genomic DNA isolated from various tissues from floxed $\left(M P Z^{+/+} / L p^{f E 2-3 / f E 2-3}\right)$ and deleted $\left(M P Z^{C r e /+} / L p^{f E 2-3 / f E 2-3}\right)$ mice. $(\mathrm{En})$ Endoneurium; $(\mathrm{PE})$ peri/epineurium; $(\mathrm{Li})$ liver; (Ad) adipose tissue; (Br) brain; (Te) testis; (Ki) kidney; (0) water. A mixture of three oligonucleotides was used. The F2/R1 primer pair allows the amplification of a 1449-bp fragment when the floxed fragment is present, and the F1/R1 primer pair allows the amplification of a 1074-bp band after the Cre-mediated excision of exons 2 and 3. Recombination is only detected in the endoneurium of $M P Z^{C r e /+} / L p^{f E 2-3 / f E 2-3}$ mice. (E) Quantitative PCR analysis of the Lpin1 expression in the endoneurium (En) and peri/epineurium (PE) isolated from wild-type controls (black bars) or mutants (full mutant: Lpin $1^{\text {fld } / f f l}$; conditional mutant: $M P Z^{\text {Crel+ }} / L p^{f E 2-3 / f E 2-3}$, gray bars). Lpin1 expression is undetectable in both endoneurial and peri/epineurial compartments of the Lpin $1^{\text {fld flld }}$ nerve. The level of expression is reduced to $\sim 25 \%$ in the endoneurium of $M P Z^{\text {Cre } /+} / L p^{f E 2-3 / f E 2-3}$ mice, while there is an increase in Lpin1 expression in the peri/epineurium of these mice. $(F)$ Western blot analysis using lipin $1 \beta$-specific antibody confirms a decrease in lipin $1 \beta$ expression in the endoneurium isolated from $M P Z^{C r e /+} / L p^{f E 2-3 / f E 2-3}$ mice compared to the controls $\left(M P Z^{+/+} / L p^{f E 2-3 / f E 2-3}\right)$. No changes in the level of lipin $1 \beta$ expression were detected in the white adipose tissue (WAT). Western blotting against tubulin was done to determine equal protein loading.

phosphatidic acid (PA) to diacylglycerol (DAG), which then can serve as a substrate for triacylglycerol (TAG) biosynthesis (Fig. 6A; Carman and Han 2006; Han et al. 2006; Donkor et al. 2007; Harris et al. 2007). PAP2, which does not require $\mathrm{Mg}^{2+}$ for its action, can also catalyze the conversion of PA into DAG. However, PAP2mediated DAG production mostly plays a role in signal transduction and does not significantly contribute to TAG biosynthesis (Coleman and Lee 2004). We mea- sured the PAP1 and PAP2 activities in the extracts of endoneurium and white adipose tissue (WAT) from adult (P56) Lpin1 mutant and wild-type mice. The PAP1 activity in endoneurium was reduced by $>90 \%$ in $\operatorname{Lpin}_{1} 1^{\text {fld } / f l d}$ mice and by approximately half in $M P Z^{C r e /+} / L p^{f E 2-3 / f E 2-3}$ conditional mutant mice, reflecting the fact that, in these animals, the lpin 1 function is disrupted only in SCs (Fig. 6B). We observed $>90 \%$ reduction of the PAP1 activity also in WAT from Lpin $1^{\text {fld } / \text { fld }}$ mice. As expected, 
A

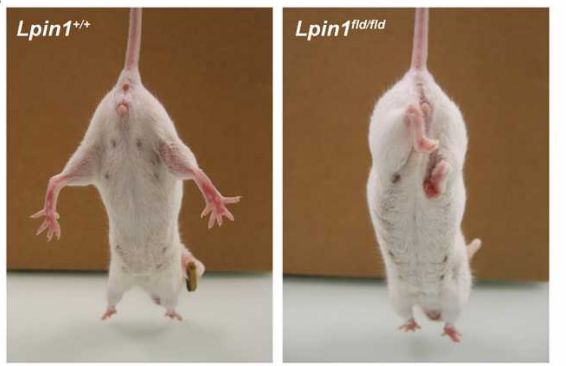

C

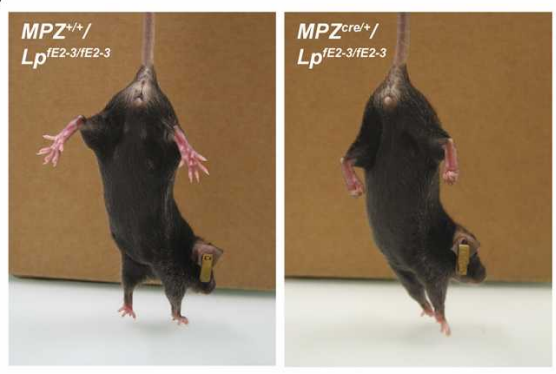

B

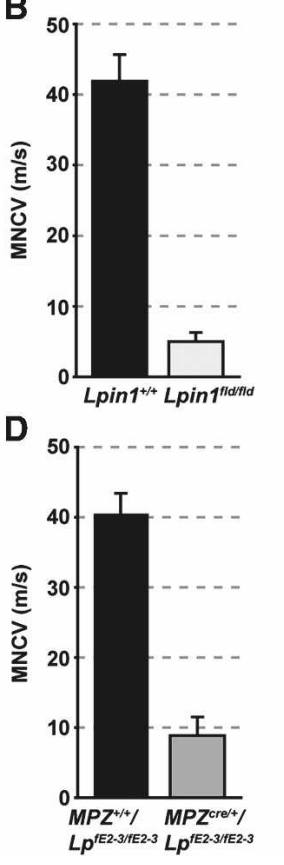

E
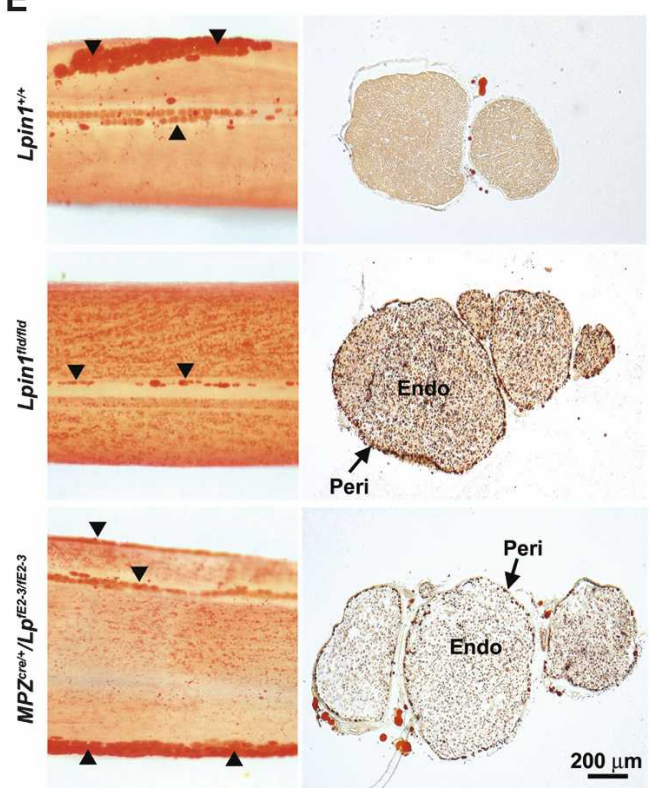

Figure 4. Specific inactivation of lipin 1 in Schwann cells leads to neuropathy. $(A, C)$ The $L p i n 1^{f l d / f l d}$ and $M P Z^{C r e /+} / L p^{f E 2-3 / f E 2-3}$ mice can be identified by their abnormal reaction to being picked up by the tail. Both mutants clench the toes of their rear feet and attempt to clasp their hind legs together. $(B, D)$ Both mutant mice show a dramatic slowing of motor nerve conduction $(n=5)$. $(E)$ Oil-red-O staining of the complete central part and transverse sections of the sciatic nerve from wild-type, Lpin $1^{f l d / f l d}$, and $M P Z^{C r e /+} / L p^{f E 2-3 / f E 2-3}$ mice. Note the reduced amount and the irregularly shaped adipocytes (arrowheads) in the Lpin $1^{\text {fld } / f l d}$ mutant, and the appearance of red spots on the nerve surface in both mutants. These spots correspond to the accumulation of Oil-red-O-positive lipidic residues in both perineurium (Peri) and endoneurium (Endo) of $L p i n 1^{f l d / f l d}$ and $M P Z^{C r e /+} / L p^{f E 2-3 / f E 2-3}$ mice. All analyses were done at P56.

in Lpin1 conditional mice, the PAP1 activity in WAT was not significantly different from that of wild-type mice. PAP2 activity was similar in tissues from Lpin $1^{f l d} / f l d$, conditional mutant, and wild-type mice (Fig. 6B). Based on the role of PAP1 in TAG synthesis (Fig. 6A), we also determined the level of TAG in endoneurium of adult (P56) Lpin1 mutant and control mice. As we did not detect any significant differences between the endoneurial TAG concentration of wild-type $(5.6[ \pm 1.1] \mu \mathrm{g}$ of TAG per centimeter of nerve) and mutant $(6.2[ \pm 0.4] \mu \mathrm{g}$ of TAG per centimeter of nerve) samples, we then assessed the level of the substrate of the PAP1 enzyme, PA, in mutant sciatic nerves compared to controls. The amount of PA in the Lpin $1^{\text {fld } l \text { fld }}$ and in the conditional mutant endoneurium was four and two times higher, respectively. The WAT from Lpin $1^{\text {fld } / f l d}$ mice showed the same elevation $(4 \times)$ in PA level, whereas the amount of PA in WAT from conditional mutant was not changed (Fig. 6C). Unlike for PA, we found no significant differences in the concentration of a precursor of PA, lysophosphatidic acid (data not shown). Together, these results indicate that lipin 1 deficiency leads to a decrease in PAP1 activity followed by significant accumulation of PA in endoneurium of both Lpin $1^{\text {fld/fld }}$ and $M P Z^{C r e /+} / L p^{f E 2-3 / f E 2-3} \mathrm{mu}-$ tant mice.

\section{PA directly affects Schwann cell differentiation state}

PA plays a role in the regulation of several important biological events, including cell growth and proliferation
(Sciorra and Morris 2002; Brindley 2004; Wang et al. 2006). To determine if the observed demyelination in mutant mice is indeed a consequence of increased PA concentration, we tested the effect of PA on myelination in vitro, using DRG explants that form myelin when ascorbic acid is added to the cultures (Fig. 7A, panels i,ii; Eldridge et al. 1987). Importantly, we observed that the continuous presence of $50 \mu \mathrm{M}$ PA very strongly (>90\%) reduced myelination as demonstrated by $\mathrm{Mpz}$ staining and Western blot analysis of Mpz expression (Fig. 7A, panels iii,iv). Nuclear staining using DAPI indicated comparable cell numbers, indicating that the loss of myelin was not due to a loss of Schwann cells. In order to determine if Schwann cells are directly affected by PA, we evaluated its effect on the forskolin-induced expression of $\mathrm{Mpz}$ protein (which is a marker of differentiated $\mathrm{SCs}$ ) in rat primary SCs. Indeed, addition of PA to the SC cultures strongly reduced forskolin-induced Mpz expression in these cells (Fig. 7B).

Schwann cell differentiation and myelination have been demonstrated to be in part controlled by the PI3KAkt and MEK-Erk intracellular signaling pathways (Harrisingh et al. 2004; Ogata et al. 2004). To determine whether PA may affect these pathways, we treated cultured mouse Schwann cells (MSC80 cell line) with 100 $\mu M$ PA and found a significant increase in the phosphorylation of Erk1/2, while Akt phosphorylation was not affected. The PA-induced Erk1/2 phosphorylation can be suppressed by the treatment of MSC80 cells with 
A

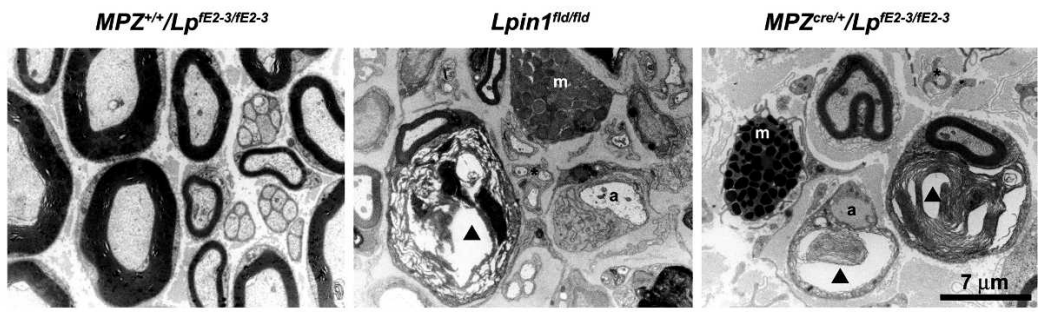

B

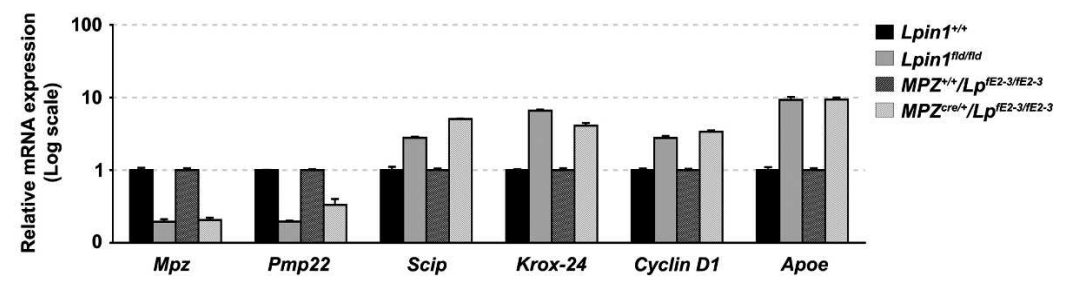

Figure 5. Ultrastructural and molecular analysis of SC myelin defects in Lpin1 mutant mice. $(A)$ Electron micrographs of transverse sections of sciatic nerves from P56 $M P Z^{+/+} / L p^{f E 2-3 / f E 2-3}$ (wild-type), Lpin1 $1^{\text {fld/fld }}$, and $M P Z^{C r e /+} / L p^{f E 2-3 / f E 2-3}$ mice. Examples of myelin-competent axons devoid of myelin (a), SC containing myelin debris $(\mathbf{\Delta})$, disorganized unmyelinated axons $\left({ }^{\star}\right)$, and mast cells $(\mathrm{m})$ present in $L p i n 1^{f l d / f l d}$ and $M P Z^{\text {Cre/+ }} / L p^{\text {fE2-3/fE2-3 }}$ endoneurium. (B) Q-PCR measurements of Mpz, Pmp22, Scip, Krox-24, Cyclin D1, and Apoe mRNAs in endoneurium of P56 control $\left(L p i n 1^{+/+}\right.$and $\left.M P Z^{+/+} / L p^{f E 2-3 / f E 2-3}\right)$ and mutant (Lpin $1^{\text {fld/fld }}$ and $\left.M P Z^{C r e /+} / L p^{f E 2-3 / f E 2-3}\right)$ mice. The data represent the mean \pm SD of triplicate measurements.
PD98059 (a known inhibitor of the MEK-Erk pathway) (Alessi et al. 1995), but is only modestly affected by the inhibitor of the PI3K, LY294002, showing that the Erk1/2 phosphorylation is not dependent on the PI3KAkt pathway (Fig. 8A). We found that PA comparably induced the Erk1/2 phosphorylation in mouse primary SCs (MPSCs) (Fig. 8A). The Erk1/2 phosphorylation in these cells goes together with an increase in the mRNA levels of markers for undifferentiated SCs (Krox-24 and Scip) (Zorick et al. 1996; Topilko et al. 1997) and of p35, a known target of the MEK-Erk pathway (Fig. 8B; Desbarats et al. 2003). The dose-response measurement in MSC80 cells showed that PA activates the MEK-Erk signaling pathway already at $1 \mu \mathrm{M}$ with the saturation of activation at $100 \mu \mathrm{M}$ (Fig. 8C). Interestingly, we observed that the MEK-Erk signaling pathway is also activated in the sciatic nerves of $L p i n 1^{f l d / f l d}$ and $M P Z^{C r e /+} / L p^{f E 2-3 / f E 2-3}$ mutant mice. There were no detectable differences between the wild-type and mutant nerves at P4. However, in sciatic nerves isolated at P10 from Lpin $1^{\text {fld/fld }}$ mice, there was a significant increase in the phosphorylation of Erk1/2, while the phosphorylation of Akt was not affected. The change in Erk $1 / 2$ phosphorylation was followed by an increase in Krox-24 and p35 expression. At P56, both mutants show significant increase in Erk1/2 phosphorylation, accompanied by increase in Krox- 24 and p35 expression, and also decrease in expression of one of the key regulators of myelination in SC, Krox-20. At this later stage, we also see an increase in the Akt phosphorylation, which probably reflects the ongoing regeneration in mutated nerve (Fig. 8D).

In order to demonstrate the physiological relevance of the MEK-Erk signaling pathway activation by PA, we treated Schwann cells and DRG explants with PA in the absence or presence of MEK-Erk signaling pathway inhibitors. The presence of PD98059 inhibitor was sufficient for partial rescue of the PA inhibitory effect on $\mathrm{Mpz}$ expression in rat primary SCs (Fig. 9A). We extended this observation using DRG explants. We induced the myelination by ascorbic acid and let it proceed for $3 \mathrm{wk}$, leading to establishment of mature myelin (Fig. 7A, panel i). The myelinated explants were then grown for an additional week in the presence of PA and in the presence of PA with addition of MEK-Erk signaling inhibitors. The presence of PA led to a substantial loss of myelinated segments (Fig. 9D,E), showing that PA is not only affecting ongoing myelination (Fig. 7A, panels i,ii) but can also induce demyelination. Importantly, the effects of PA were partially reverted by MEK-Erk inhibitor PD98059 and almost completely reverted by another MEK-Erk inhibitor, U0126 (Fig. 9D,E; Harrisingh et al. 2004). Finally, to further link the observed demyelinating phenotype to the intracellular PA accumulation, we used a known PAP1 inhibitor, propranolol (Eichberg and Zhu 1992). Similar to direct treatment with PA, incubation of rat primary SCs and DRG explants in the presence of propranolol led to a reduction in $\mathrm{Mpz}$ protein and mRNA expression in cultured cells (Fig. 9B,C) or demyelination in explants (Fig. 9D,E). These results therefore strongly suggest that PA plays a role in the determination of the SC differentiation state via activation of the MEK-Erk pathway.

\section{Discussion}

\section{Cell-autonomous SC lipin 1 function in myelination}

Using a SC-specific knockout strategy, we showed that cell-autonomous lipin 1 function is required for ongoing myelination in the PNS. Overall, our characterization of PNS development in Lpin $1^{\text {fld } / f l d}$ mice revealed a similar progression in peripheral neuropathy development as previously reported (Langner et al. 1991). We were unable to detect any changes in the peripheral nerve at pre-myelinating and early myelinating stages (P0-P4). However, starting from P10, the myelin was substantially thinner as compared to controls. At P56, the nerves from both complete and conditional mutants showed marked demyelination as demonstrated by reduced myelin marker mRNA and protein expression, the presence 
A

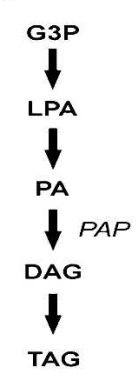

B

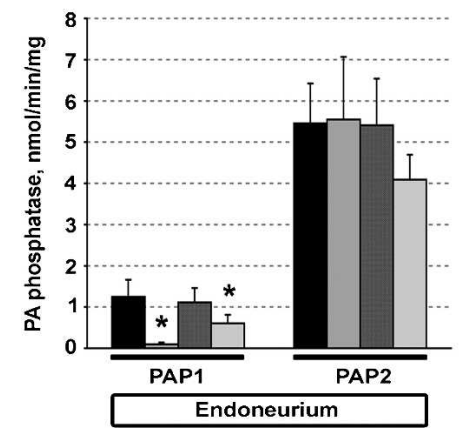

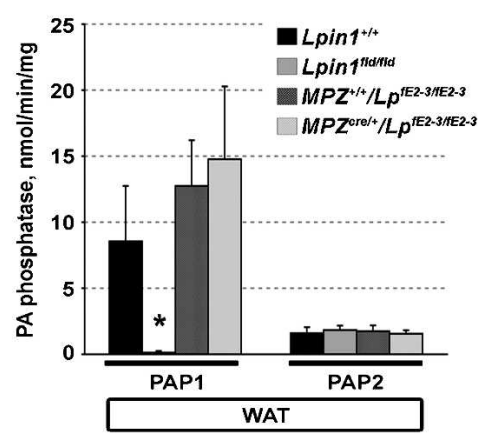

C

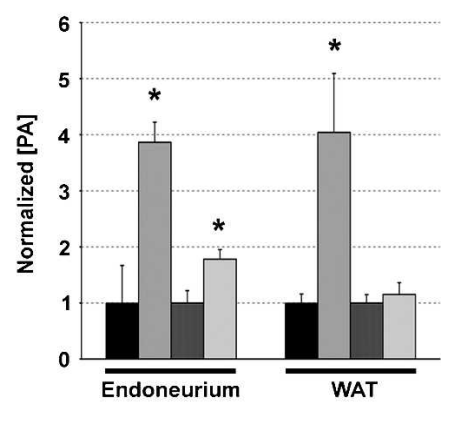

Figure 6. Disruption of the Lpin1 gene leads to decrease in endoneurial phosphatidic acid phosphatase activity and accumulation of phosphatidic acid. (A) Overview of the triacylglycerol synthesis pathway. (G3P) Glycerol-3-phosphate; (LPA) lysophosphatidic acid; (PA) phosphatidic acid; (DAG) diacylglycerol; (TAG) triacylglycerol; (PAP) phosphatidic acid phosphatase. (B) Mg ${ }^{2+}$-dependent (PAP1/ Lipin 1) and $\mathrm{Mg}^{2+}$-independent PA phosphatase activity (PAP2) measurements in endoneurium and white adipose tissue (WAT) from control (Lpin $1^{+/+}$and $\left.M P Z^{+/+} / L p^{f E 2-3 / f E 2-3}\right)$ and mutant (Lpin $1^{f l d / f l d}$ and $\left.M P Z^{C r e /+} / L p^{f E 2-3 / f E 2-3}\right)$ animals. $(C)$ PA concentrations were measured in endoneurium and in WAT from P56 control (Lpin $1^{+/+}$and $\left.M P Z^{+/+} / L p^{f E 2-3 / f E 2-3}\right)$ and mutant $\left(L p i n 1^{f l d / f l d}\right.$ and $\left.M P Z^{C r e /+}\right)$ $\left.L p^{f E 2-3 / f E 2-3}\right)$ mice. The values measured in control animals were adjusted to 1 , and the data from mutant animals were consequently normalized. Standard deviations were calculated from triplicate experiments. The legend present in $B$ is also valid for $C$. $\left({ }^{\star}\right) p<0.05$ versus controls.

of a large fraction of SCs with myelin debris, an increase in SC proliferation and apoptosis, macrophage infiltration, and increased presence of mast cells. The presence of disorganized Remak bundles containing small-diameter nerve fibers indicates that nonmyelinating Schwann cells are also affected by Lpin 1 mutation. The demyelination led to functional impairment as detected by decreased nerve conduction velocity. Interestingly, the demyelinating phenotype can easily be revealed by Oilred-O staining. In the wild-type nerve, this staining produced light-red coloration of myelin. However, in both mutants, Oil-red-O staining revealed loss of myelin, accompanied by accumulation of lipidic droplets in endoneurium and in perineurium, which probably represent residual myelin debris and previously documented accumulation of cholesterol esters (Langner et al. 1991).

The role of lipid metabolism in myelination was the subject of previous genetic studies. Conditional inactivation of squalene synthase disrupts cholesterol synthesis in oligodendrocytes, leading to CNS hypomyelination that surprisingly improves with age, probably due to horizontal cholesterol transfer from unaffected cells (Saher et al. 2005). The genetic inactivation of CGT, the enzyme required for myelin galactolipid synthesis, leads only to minor defects in the PNS mostly affecting the structure of axo-glial junctions. This is unexpected since both galactolipid galactocerebroside and its sulfated derivative, sulfatide, are highly enriched in myelin membrane. However, the SCs may compensate for the missing galactolipids via accumulation of glucosylceramide (Dupree et al. 1999; Marcus and Popko 2002). Our observation that Lpin 1 mutant mice show strong demyelination therefore suggests a different underlying pathological mechanism.

\section{Biochemical function of lipin 1 in the nerve}

Lipin 1 was recently discovered to be the $\mathrm{Mg}^{2+}$-dependent phosphatidate phosphatase (PAP1) involved in de- phosphorylation of PA-producing diacylglycerol and $\mathrm{P}_{\mathrm{i}}$ (Han et al. 2006; Donkor et al. 2007; Harris et al. 2007). This reaction is essential for biosynthesis of TAG via the glycerol-3-phosphate pathway, which is crucial for the majority of de novo synthesized TAG in mammalian cells (Coleman and Lee 2004). Our data showing the decreased PAP1 activity in endoneurium from both Lpin $1^{\text {fld/fld }}$ and $M P Z^{C r e /+} / L p^{f E 2-3 / f E 2-3}$ mice clearly demonstrated that the Lpin1-encoded protein serves as the PAP1 enzyme in sciatic nerve. Interestingly, the decreased PAP1 activity apparently cannot be fully replaced by, nor is affecting, the PAP2 activity, which is approximately five times higher in the endoneurium of control mice and does not increase in mutants. The ratio of PAP1 to PAP2 level is reversed in WAT, where PAP1 is 10 times more abundant than PAP2, confirming the previously reported data (Donkor et al. 2007). The incapacity of PAP2 (which is also known under the name lipid phosphate phosphatase- 1 and is encoded by a family of Ppap2 genes) to compensate for PAP1 function may come from differences in their subcellular location. PAP1 is mostly a cytosolic/endoplasmic reticulum protein, while PAP2 is an integral plasma membrane protein (Coleman and Lee 2004). Lipin 1 protein exists in two isoforms generated via alternative splicing of Lpin1 mRNA (Peterfy et al. 2005). Our data showed that the $L \operatorname{pin} 1 \beta$ form is the predominant form present in endoneurium of peripheral nerve isolated from adult (P56) mice, while $L$ pin $1 \alpha$ is only detectable during early postnatal development (P0-P10). Also, using lipin $1 \beta$-specific antibodies, we were able to show its predominant cytoplasmic localization compatible with its function as PAP1. This profile of expression is very similar to the previously observed lipin 1 isoform expression in 3T3-L1 adipocytes, where lipin $1 \beta$ expression increases during adipocyte differentiation and is predominantly located in the cytoplasm (Peterfy et al. 2005). The role of lipin $1 \alpha$ in the nerve remains unclear at present. One possibility is 
A
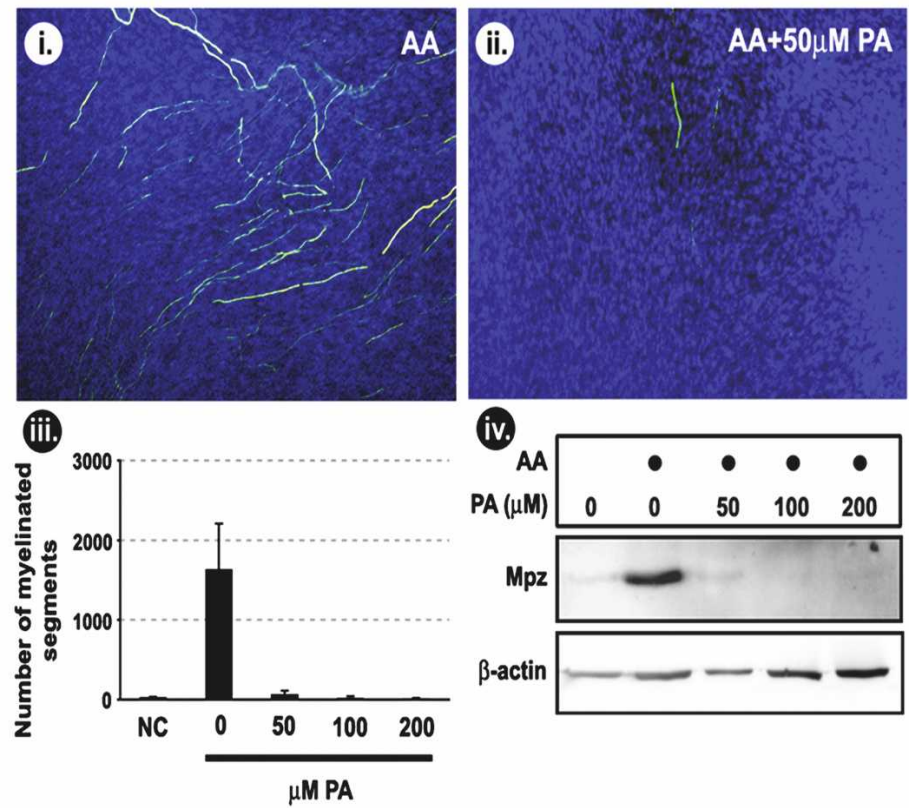

(iv)

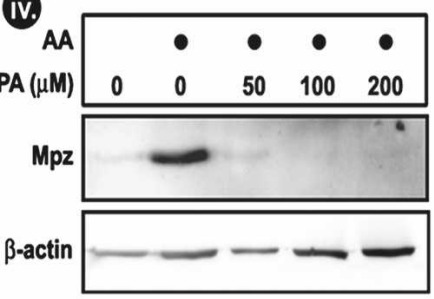

B

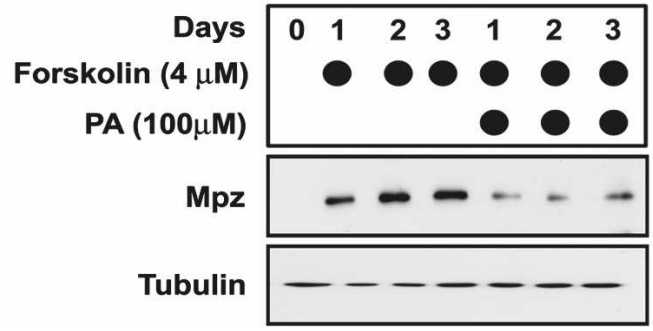

Figure 7. PA interferes with Schwann cell myelination. (A, panels i,ii) DRG explants were cultured for 3 wk in medium containing $50 \mu \mathrm{g} / \mathrm{mL}$ (of ascorbic acid (AA), to induce myelination, and in the presence or absence of $50 \mu \mathrm{M}$ of PA. The myelination level was evaluated by immunohistochemical staining with $\mathrm{Mpz}$ antibody (in green). Cell nuclei were stained with DAPI. (Panel iii) The number of myelinated segments in DRGs cultured in the presence of increasing concentrations of PA were counted; (NC) negative control grown in the absence of AA and PA. Standard deviations were calculated from triplicate experiments. (Panel iv) Western blot evaluation of the amount of Mpz expression in DRG explants cultured in presence of AA and increasing amounts of PA. Western blotting against $\beta$-actin was used to control for equal protein loading. $(B)$ Western blot measurement of $\mathrm{Mpz}$ expression in rat primary SCs induced to express myelin markers by $4 \mu \mathrm{M}$ forskolin, grown for, respectively, 1, 2, or $3 \mathrm{~d}$ in the presence or absence of $100 \mu \mathrm{M}$ PA. Western blotting against tubulin was done to determine equal protein loading. that lipin $1 \alpha$, which is mostly nuclear, may potentially act as a transcriptional regulator during peripheral nerve maturation, as previously shown in hepatic cells (Peterfy et al. 2005; Finck et al. 2006).

\section{Role of phosphatidic acid in Schwann cell fate determination}

We found that PAP1 inactivation leads to a previously ignored accumulation of its substrate, PA, in endoneurium of Lpin1 $1^{f l d / f l d}$ or $M P Z^{C r e /+} / L p^{f E 2-3 / f E 2-3}$ P56 mice, while the concentration of its precursor LPA was not increased. This is of interest because although the role of LPA in SC survival and morphology was previously described (Weiner and Chun 1999; Weiner et al. 2001), the role of PA remains unknown. Our observation that either the presence of exogenous PA or propranolol-mediated intracellular accumulation of PA inhibited both DRG explant myelination and Schwann cells' Mpz expression indicates that PA directly affects SCs and is therefore involved in the demyelination observed in the Lpin1 mutant mice.

Although the exact mechanism of PA action on SCs remains to be clarified, our data clearly demonstrate that the MEK-Erk pathway is involved. In vivo, in Lpin1 mu- tant mice, we observed that the increase in endoneurial PA concentration due to PAP1 inactivation led to the activation of the MEK-Erk pathway that was detectable at P10 and thereby concomitant with the observed onset of neuropathy. In the DRG explants cultured in the presence of exogenous PA, the process of demyelination could be rescued by inhibitors of the MEK-Erk pathway, PD98059 and U0126, further implicating this pathway in the observed action of PA. Finally, in cultured SCs, the increase in extracellular PA concentration also led to MEK-Erk pathway activation, to induction of immature SC markers expression (Krox-24, Scip), and to reduction in levels of Mpz protein (marker of differentiated SCs), thus reproducing the in vivo observations in Lpin1 mutant mice.

The central role of the MEK-Erk pathway in the observed SC demyelination is supported by recent evidence that this pathway can drive Schwann cell dedifferentiation (Harrisingh et al. 2004) and that Erk signaling mediates demyelination following nerve injury (Sheu et al. 2000; Harrisingh et al. 2004) or Mycobacterium leprae infection (Tapinos et al. 2006). Interestingly, PA-mediated translocation of Raf-1 from cytosol to plasma membrane, where it can interact with Ras, could be the trigger for the observed activation of the MEK-Erk pathway, 
Nadra et al.

A

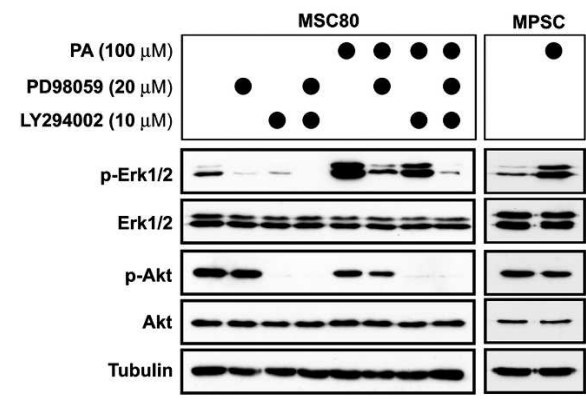

C

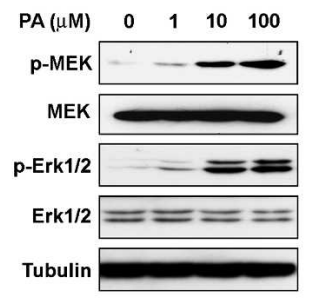

B

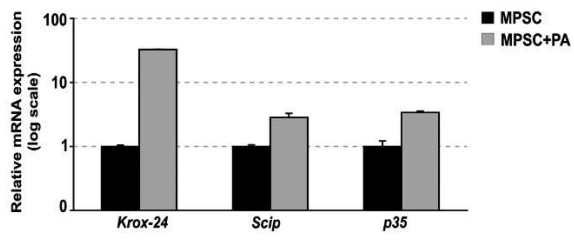

D

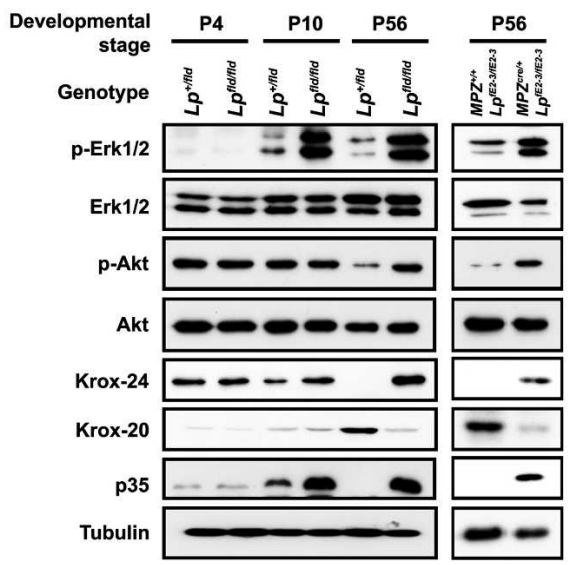

Figure 8. Characterization of intracellular signaling pathways affected by PA in Schwann cells. (A) The mouse SC line (MSC80) and mouse primary SCs (MPSC) from P4 wild-type sciatic nerve were treated for $1 \mathrm{~h}$ with $100 \mu \mathrm{M}$ PA in the presence or absence of MEK-Erk pathway (20 $\mu$ M PD98059) or PI3K-Akt pathway (10 $\mu$ M LY294002) inhibitors. Activation of Erk1/2 and Akt was evaluated by specific antibodies recognizing their phosphorylated forms (p-Erk1/2 and p-Akt). (B) Quantitative PCR evaluation of Krox-24 and Scip (immature SC markers) and of $p 35$ (downstream target of p-Erk1/2 signaling) expression in MPSC cells grown in the presence or absence of $100 \mu \mathrm{M}$ PA (data are represented as fold increase above control levels). Standard deviations were calculated from triplicate experiments. $(C)$ MSC80 cells were treated for $1 \mathrm{~h}$ with increasing concentrations $(0-100 \mu M)$ of PA. Activation of MEK and Erk1/2 was evaluated by specific antibodies recognizing their phosphorylated forms (p-MEK and p-Erk1/2). (D) Western blot analysis of samples from complete sciatic nerve at P4 and P10 and of the endoneurium fraction of P56 sciatic nerve from control $\left(L p^{+/ f l d}\right.$ and $\left.M P Z^{+/+} / L p^{f E 2-3 / f E 2-3}\right)$ and mutant mice $\left(L p^{f l d / f l d}\right.$ and $\left.M P Z^{C r e /+} / L p^{f E 2-3 / f E 2-3}\right)$. In addition to the antibodies used in $A$, levels of Krox-24, p35, and Krox-20 (marker of myelinating SCs) were evaluated. Western blotting against tubulin was done in $A, C$, and $D$ to determine equal protein loading.

bypassing the necessity of signaling through a cell surface receptor (Rizzo et al. 1999; Andresen et al. 2002). The gene expression changes detected in mutant nerves may be conveyed by MEK-Erk-regulated transcription factors CREB and Elk-1 that recognize CRE and SRE sites, respectively. These sequence motifs are present in 5 ' regions of several immediate-early response genes, including Krox-24 (Bozon et al. 2003). The observed changes in Krox-24 (marker of immature SCs) and Krox20 (marker of myelinating SCs) expression suggest that the PA-activated MEK-Erk pathway may affect the balance between these two transcription factors and thus participates, especially in pathological situations, in the choice between myelinating and non-myelinating Schwann cell phenotypes (Topilko et al. 1997; Cavaletti et al. 2007).

Inactivation of PAP1 function may also lead to a decrease in the amount of DAG and TAG that are downstream from its action. However, we were unable to detect any significant changes in TAG concentration in endoneurium from P56 Lpin1 mutant mice, confirming the previous measurements (Langner et al. 1991). This may partially reflect the fact that the overall concentration of TAG in nerve is relatively low (Yao 1985). The previously reported reduction of DAG in yeast missing lipin 1 function (Han et al. 2006) and measured decrease in the concentration of phosphatidylethanolamine and phosphatidylserine (synthesized from DAG) in nerves of Lpin $1^{\text {fld/fld }}$ (Langner et al. 1991), however, suggest that phospholipid biosynthesis may also be affected in mutant endoneurium, potentially contributing to the development of neuropathy in the mutant nerve.

Lpin1 mutant mice as a model of lipid metabolism-related conditions affecting peripheral nerve

Our observation that Schwann cell in situ lipid homeostasis plays a crucial role in myelin synthesis and maintenance may provide insight into the lipid metabolism affecting conditions associated with peripheral neuropa- 
A

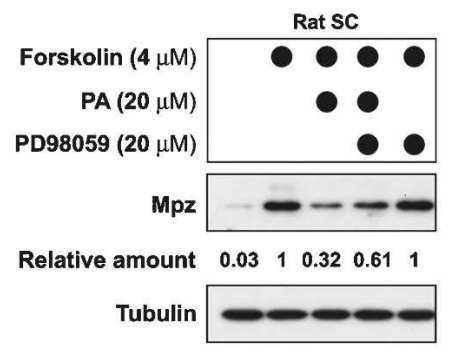

D
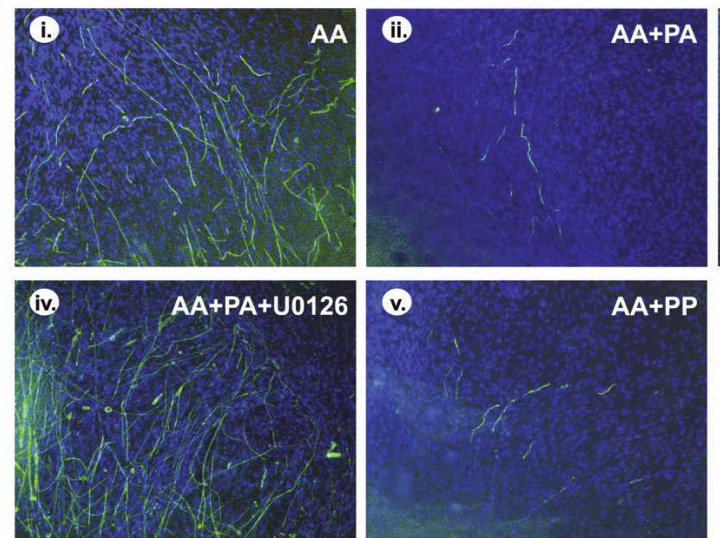

B

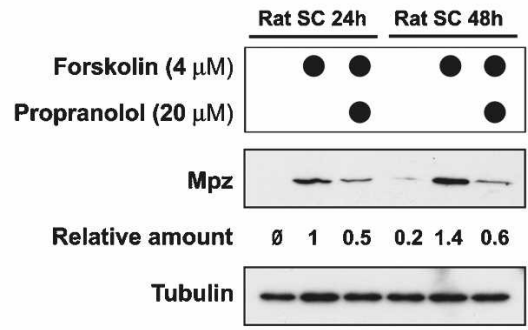

C

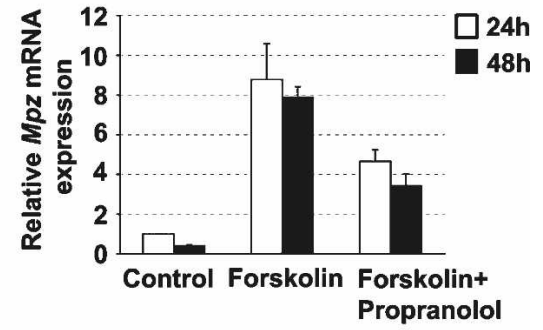

$\mathbf{E}$

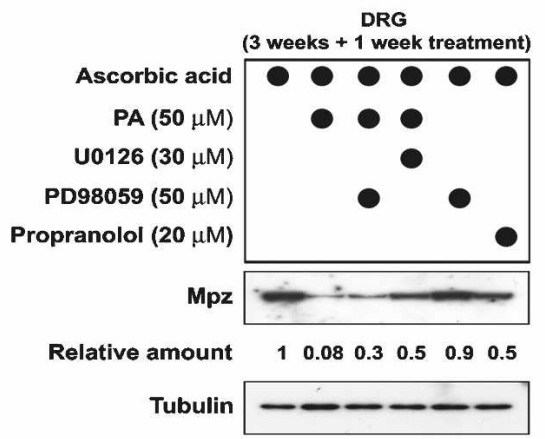

Figure 9. Activation of the MEK-Erk pathway contributes to PA-mediated demyelination. (A) Western blot measurement of Mpz expression in rat primary SCs induced to express myelin markers by $4 \mu \mathrm{M}$ forskolin, grown for $24 \mathrm{~h}$ in the presence or absence of 20 $\mu \mathrm{M}$ PA and the MEK-Erk pathway inhibitor (20 $\mu$ M PD98059). (B) Western blot measurement of Mpz expression in rat primary SCs induced to express myelin markers by $4 \mu \mathrm{M}$ forskolin, grown for 24 or $48 \mathrm{~h}$ in the presence or absence of $20 \mu \mathrm{M}$ phosphatidate phosphatase 1 inhibitor propranolol. $(C)$ Quantitative PCR evaluation of $\mathrm{Mpz}$ expression in rat primary SCs induced to express myelin markers by $4 \mu \mathrm{M}$ forskolin, grown for 24 or $48 \mathrm{~h}$ in the presence or absence of $20 \mu \mathrm{M}$ propranolol. Data are represented as fold increase above control level at $24 \mathrm{~h}$. Standard deviations were calculated from triplicate experiments. (D) DRG explants were cultured for 3 wk in medium containing $50 \mu \mathrm{g} / \mathrm{mL}$ of ascorbic acid (AA), to induce myelination. The explants were then cultured for an additional week in the presence of $50 \mu \mathrm{g} / \mathrm{mL}$ ascorbic acid (AA, panel i); in the presence of $50 \mu \mathrm{g} / \mathrm{mL}$ ascorbic acid and $50 \mu M$ PA (AA + PA, panel ii); in the presence of $50 \mu \mathrm{g} / \mathrm{mL}$ ascorbic acid, $50 \mu \mathrm{M} \mathrm{PA}$, and $50 \mu \mathrm{M}$ PD98059 (AA + PA + PD, panel iii); in the presence of $50 \mu \mathrm{g} / \mathrm{mL}$ ascorbic acid, $50 \mu \mathrm{M} \mathrm{PA}$, and $30 \mu \mathrm{M}$ U0126 (AA + PA + U0126, panel iv) and in the presence of $50 \mu \mathrm{g} / \mathrm{mL}$ ascorbic acid and $20 \mu \mathrm{M}$ propranolol (AA + PP, panel $v$ ). The level of myelination was evaluated by immunohistochemical staining with Mpz antibody (in green). Cell nuclei were stained with DAPI. (Panel vi) The number of myelinated segments in DRGs cultured under conditions described in panels $i-V$ were counted. Standard deviations were calculated from triplicate experiments. $(E)$ Western blot measurement of Mpz expression in DRG explants cultured under conditions described in $D .(A, B, E)$ Western blotting against tubulin was done to determine equal protein loading. $(A, B, E)$ The relative amount represents intensity of the Mpz band after correction for loading difference by measuring the amount of tubulin.

thy. Diabetic peripheral neuropathy (DPN) is the most common complication of diabetes mellitus, affecting $\sim 30 \%$ of diabetic patients (Sima 2003). Reduced levels of Lpin1 expression in WAT and liver of insulin-resistant human subjects were previously reported (Yao-Borengasser et al. 2006; Croce et al. 2007), suggesting that possible variation in Schwann cell Lpin1 expression may play a role in DPN. Also, peripheral neuropathy and lipodystrophy are major complications in HIV patients undergoing antiretroviral therapy (Keswani et al. 2002). It was found that Lpin1 expression is reduced in adipose tissue of these patients (Lindegaard et al. 2007). If Lpin1 expression is affected in SCs of these patients as well, this may explain the mechanisms underling the peripheral neuropathy observed in these patients. We are currently evaluating both of these hypotheses.
In conclusion, our analysis of Lpin1 mutant mice demonstrated that disturbed lipid homeostasis within Schwann cells interferes with normal myelination and leads to peripheral neuropathy. Surprisingly, we discovered that phosphatidic acid plays a key role in the observed Schwann cell dedifferentiation. These data confirm our hypothesis that local regulation of lipid metabolism in peripheral nerve plays a crucial role in its function (Verheijen et al. 2003) and provide important insight into possible pathological consequences of diseases affecting lipid metabolism in Schwann cells.

\section{Materials and methods}

\section{Animals}

BALB/cByJ-Lpin ${ }^{f l d /+}$ mice were obtained from the Jackson Laboratory. Throughout the text, mice of the $L p i n 1^{\text {fld/fld }}$ and $M P Z^{C r e /+} /$ 
$L p^{f E 2-3 / f E 2-3}$ genotypes are referred to as "Lpin1 mutants." Mice of $L p i n 1^{f l d /+}, L p i n 1^{+/+}, M P Z^{+/+} / L p^{f E 2-3 / f E 2-3}, M P Z^{+/+} / L p^{f E 2-3 /+}$, and $M P Z^{C r e /+} / L p^{f E 2-3 /+}$ genotypes are all referred to as "wild-type." Experiments were performed in accordance with the legal requirements of the University of Lausanne and the Canton of Vaud (Switzerland).

\section{Generation of mice with the floxed Lpin 1 gene}

We screened the RPCI-22 mouse genomic BAC library filters containing mouse genomic DNA from the 129S6/SvEvTac mouse strain, which is isogenic with the ES cells used further (filters were obtained from BACPAC Resources; http://bacpac. chori.org/mouse22.htm) and isolated clones containing exons 2 and 3 of the Lpin1 gene. A recombineering-based approach was used to perform the subsequent cloning steps that eliminates the necessity of specific restriction enzyme sites since it uses homologous recombination (Liu et al. 2003). Using this approach, the targeting vector in which there is a $\operatorname{lox} P$ site just in front of exon 2 and an FRT-neo-FRT-loxP cassette just after exon 3 was prepared (Fig. 3A). The linearized targeting construct was electroporated into the ES cells, which were then grown in medium containing G418. Clones positive for homologous recombination were selected by Southern blotting and used for blastocyst injection and subsequent development of mice with the targeted allele (Lpin $\left.1^{f E 2-3}\right)$ (Fig. $\left.3 \mathrm{~B}\right)$. In order to generate mice with the Lpin1 gene selectively inactivated only in Schwann cells, the Lpin $1^{f E 2-3 / f E 2-3}$ mice were mated with $m P_{O} T O T A(C r e)$ transgenic mice (Feltri et al. 1999). The double heterozygous mice $\left(M P Z^{C r e /+} / L p^{f E 2-3 /+}\right)$ were mated with homozygous $L p i n 1^{f E 2-3 / f E 2-3}$ mice, leading to the generation of conditional knockout mice $\left(M P Z^{C r e /+} / L p^{f E 2-3 / f E 2-3}\right)$. The LpCond $\mathrm{F}$ and LpCond $\mathrm{R}$ primers were used for genotyping of generated mice, amplifying a 780-bp product from the $L p i n 1^{\text {fE2-3 }}$ allele and a 740-bp product from the $\operatorname{Lpin}^{+}$allele. The P0-CreF and P0CreR primer set amplifying the 492-bp PCR product was used for the detection of the MPZ ${ }^{C r e}$ allele. The combination of primers F1, F2, and R1 (Fig. 3B) was used to detect the Lpin $1^{\Delta E 2-3}$ allele with deleted exons 2 and 3. Detailed PCR conditions will be available upon request. All primer sequences are in Supplemental Table 1.

\section{Sciatic motor nerve conduction velocity (MNCV)}

The P56 animals were anesthetized with $10 \mu \mathrm{L}$ per gram of mouse body weight of the mixture of Ketanarkon 100 (diluted 10x; Streuli) with Rompun (diluted 20x; Bayer) in PBS. The left and right sciatic nerves were stimulated at the sciatic notch and distally at the ankle via bipolar electrodes with supramaximal square-wave pulses $(5 \mathrm{~V})$ of $0.05 \mathrm{msec}$. The latencies of the compound muscle action potentials were recorded by a bipolar electrode inserted between digits 2 and 3 of the hind paw and measured from the stimulus artifact to the onset of the negative $\mathrm{M}$-wave deflection. MNCV was calculated by subtracting the distal latency from the proximal latency, and the result was divided by the distance between the stimulating and recording electrodes.

\section{Microdissection of sciatic nerve}

Sciatic nerves from adult (P56) mice were placed in ice-cold PBS $(\mathrm{pH}$ 7.4). The perineurium and epineurium were gently dissected away from the endoneurium along the whole length of the nerve as previously described (Verheijen et al. 2003).

\section{Western blotting}

Cells or tissues were lysed in ice-cold lysis buffer $(20 \mathrm{mM}$ $\mathrm{Na}_{2} \mathrm{H}_{2} \mathrm{PO}_{4}, 250 \mathrm{mM} \mathrm{NaCl}$, Triton X-100 1\%, SDS 0.1\%) supple- mented with Complete protease inhibitors (Roche). Protein levels were quantified using the Bio-Rad protein assay with BSA as a standard. Equal amounts of protein extracts were resolved by $10 \%$ SDS-PAGE and electro-transferred onto a polyvinylidene difluoride (PVDF) membrane (Amersham Biosciences). Blots were blocked in tris-buffered saline containing $0.1 \%$ Tween (TBS-T) supplemented with $4 \%$ milk powder and subsequently incubated overnight at $4^{\circ} \mathrm{C}$ in the same buffer supplemented with antibodies against Akt, phospho-Akt (Ser473), MEK1/2, phospho-MEK1/2 (Ser221), p44/42 MAP kinase, phospho-p44/ 42 MAPK (Thr202/Tyr204), tubulin (all from Cell Signaling), Krox-20 (Egr-2, Covance), Oct-6/Scip and Krox-24/Egr-1 (Abcam), p35 (Santa Cruz Biotechnologies), Myelin protein zero (Mpz) (provided by J.J. Archelos), $\beta$ actin (Sigma), and Lipin $1 \beta$ (generated in this study). After washing in TBS-T, blots were exposed to the appropriate horseradish peroxidase-conjugated secondary antibodies (Dako) in TBS- $\mathrm{T}$ for $1 \mathrm{~h}$ at room temperature. Finally, blots were developed using the ECL reagents (Pierce) and Kodak Scientific Imaging Films (Kodak).

\section{Quantitative RT-PCR}

For all analyses, total RNA from complete sciatic nerve, from endoneurium and from peri-epineurium was isolated using the Qiagen RNeasy lipid tissue kit (Qiagen) following the manufacturer's instructions. Total RNA from liver, MSC80, mouse, and rat primary Schwann cells was isolated in TRIzol (Invitrogen) reagent and purified with the RNeasy kit (Qiagen). RNA quality was verified by agarose gel and/or by Qiaxcel capillary electrophoresis device (Qiagen), and the concentration was determined by a ND-1000 Spectrophotometer (NanoDrop). Total RNA (250-500 ng) was subjected to reverse transcription using the SuperScript III First-Strand Synthesis System for RT-PCR (Invitrogen) following the manufacturer's instructions. The resulting cDNA was used as a template for quantitative PCR (Q-PCR) as described previously (de Preux et al. 2007). Results were normalized using the reference genes cyclophilin or ubiquitin. See Supplemental Table 1 for a complete list of oligonucleotides used for Q-PCR.

\section{Immunohistochemistry}

Unless specifically stated, for all histological analyses, we used mice that were perfused with $4 \%$ paraformaldehyde (PFA) in PBS for $10 \mathrm{~min}$. The sciatic nerves were dissected and embedded in OCT medium (Sakura) and longitudinal or cross-sections were prepared. Prior to specific staining, the slides were postfixed in $4 \%$ PFA for $10 \mathrm{~min}$.

For immunohistochemistry, slides were briefly $(30 \mathrm{sec})$ washed in PBS and blocked for $1 \mathrm{~h}$ using $5 \%$ normal goat serum (DAKO) and $0.3 \%$ Triton X-100 (Merck) in PBS (PBS-T). Slides were incubated overnight at $4^{\circ} \mathrm{C}$ with primary antibodies diluted in PBS-T. The following primary antibodies were used: anti-Lipin $1 \beta$ (rabbit, 1:200; generated in this study), Oct-6/Scip IgG (goat, 1:200; Abcam), Krox-20 IgG (rabbit, 1:100; Covance), MBP IgG (rat, 1:100; Chemicon), and F4/80 IgG (rat, 1:1000; Serotec). The slides were than washed in PBS-T and hybridized with the appropriate secondary fluorescent antibodies (Alexa Fluor 594 or 488 conjugated anti-rabbit, mouse, and goat; all at a dilution of 1:200; Invitrogen) for $2 \mathrm{~h}$ at room temperature. Slides were washed in PBS-T and mounted with Vectashield mounting medium containing DAPI to counterstain cell nuclei (Vector Laboratories). Sections were visualized using a Zeiss Axioplan 2 microscope with an AxioCam MRc camera and AxioVision release 4.5 software (Zeiss). 
Lipin $1 \beta$ antibody

A rabbit anti-lipin $1 \beta$ antibody was generated with a peptide (SLVDCQRTPPHLAEGV) specific for the mouse lipin $1 \beta$ isoform (Eurogentec) and used at 1:1000 dilution for Western blot and 1:200 for immunohistochemistry.

\section{Oil-red-O staining}

A fresh working solution of Oil-red-O (Sigma) was prepared by dilution of the Oil-red-O stock solution $15 \mathrm{~g} / \mathrm{L}$ in $98 \%$ isopropanol) in distilled water at a ratio of 3:2. The working solution was allowed to stand for $10 \mathrm{~min}$ after mixing and was filtered with a $0.45-\mu \mathrm{m}$ pore-size filter. Subsequently, sciatic nerve cross-sections were briefly $(30 \mathrm{sec}$ ) washed in PBS, stained with the filtered working solution of Oil-red-O for $10 \mathrm{~min}$, and washed for $10 \mathrm{~min}$ in demineralized water (room temperature). The slides were allowed to dry and were mounted with Vectashield mounting medium (Vector Laboratories).

Terminal deoxynucleotidyl transferase-mediated biotinylated UTP nick end-labeling (TUNEL) assay

Sciatic nerve longitudinal cryosections were prepared and postfixed in 4\% PFA in PBS (pH 7.4) for 20 min and then permeabilized with $0.1 \%$ Triton X-100/0.1\% sodium citrate on ice for 2 min. TUNEL was performed using the In Situ Cell Death Detection kit (Roche) according to the manufacturer's instructions. Cell nuclei were counterstained with DAPI.

\section{BrdU incorporation assay}

P56 mice were injected intraperitoneally with $100 \mu \mathrm{g}$ of BrdU per gram of body weight. Six hours later, the sciatic nerves were dissected, fixed in $4 \%$ paraformaldehyde for $24 \mathrm{~h}$, and embedded in OCT medium. Longitudinal cryosections were prepared, post-fixed in $4 \%$ paraformaldehyde $(10 \mathrm{~min})$, denatured with 2 $\mathrm{N} \mathrm{HCl}$ for $20 \mathrm{~min}$ at $37^{\circ} \mathrm{C}$, and neutralized in $0.1 \mathrm{M}$ sodium borate $(\mathrm{pH} 8.5)$ for $10 \mathrm{~min}$. Sections were incubated with rat anti-BrdU (at a 1:200 dilution; Abcam) in 0.3\% Triton X-100 overnight at $4{ }^{\circ} \mathrm{C}$. Next day, the sections were incubated with anti-rat secondary antibody conjugated to Alexa Fluor 594 (at a 1:200 dilution; Invitrogen) and visualized with fluorescence microscopy. The nuclei were counterstained with DAPI.

\section{Electron microscopy}

P56 mice were perfused with 2\% PFA and 2\% glutaraldehyde in $0.1 \mathrm{M}$ cacodylate buffer $(\mathrm{pH} 7.3)$ for $10 \mathrm{~min}$. For P4 and P10, the nerves were dissected from unperfused animals and processed as follows: all tissues were immersed in the fixative solution $(2 \%$ PFA, $2 \%$ glutaraldehyde, $0.1 \mathrm{M}$ cacodylate buffer at $\mathrm{pH} 7.3$ ) for $2 \mathrm{~h}$ at $4{ }^{\circ} \mathrm{C}$, washed in $0.1 \mathrm{M}$ cacodylate buffer, and osmicated for $4 \mathrm{~h}$ in $1 \% \mathrm{OsO}_{4}$ (Fluka). Nerves were rinsed in $0.1 \mathrm{M}$ cacodylate buffer, dehydrated, and embedded in epoxy 812-Araldite (Polysciences). One-micrometer sections were stained with $1 \%$ toluidine blue and examined by light microscopy. Ultra-thin sections were subsequently cut, collected on cellodin-coated single slot grids, and stained with uranyl acetate and lead citrate. Photographs were obtained using a JEOL 1200EX electron microscope.

\section{Morphometric analysis}

Semi-thin nerve cross-sections were stained with $1 \%$ toluidine blue and digitalized using the AxioVision release 4.5 software
(Zeiss). For each myelinated axon present, both an axonal area (defined by the inner limit of the myelin sheath) and a total fiber area (defined by the outer limit of the myelin sheath) were automatically measured with an image analysis software (G-ratio calculator 1.0, Image J plug-in, Yannick Krempp, Cellular Imaging Facility, Lausanne, Switzerland). The g-ratio was calculated by dividing the axon area by total fiber area. Each experimental group consisted of three mice.

\section{Cell culture}

MSC80 cell line The mouse Schwann cell line (MSC80) (Boutry et al. 1992) was maintained in DMEM supplemented with $10 \%$ FCS, $100 \mathrm{U} / \mathrm{mL}$ penicillin, $100 \mu \mathrm{g} / \mathrm{mL}$ streptomycin, and $0.5 \mu \mathrm{g} / \mathrm{mL}$ fungizone (all reagents were from Invitrogen). In order to evaluate activation of either the MEK-Erk or PI3K-Akt pathways, the cells were grown for $1 \mathrm{~h}$ in the presence or absence of $100 \mu \mathrm{M}$ phosphatidic acid (Sigma), PD98059 (20 $\mu \mathrm{M}$; Cell Signaling), and LY294002 (10 $\mu \mathrm{M}$; Cell Signaling).

Mouse primary Schwann cell culture Mouse SC cultures were established from neonatal sciatic nerves as described (Weinmaster and Lemke 1990). Sciatic nerves dissected from P2 mice were enzymatically treated with $0.5 \mathrm{mg} / \mathrm{mL}$ collagenase type I (Invitrogen) and $2.5 \mathrm{mg} / \mathrm{mL}$ dispase II (Roche), followed by mechanical dissociation through 18,21, and 23 gauge needles. The cell suspension was filtered through a $53-\mu m$ nylon mesh, and cells were plated on tissue plastic culture dish in Dulbecco's modified Eagle's medium (DMEM; Invitrogen) supplemented with $10 \%$ fetal calf serum (FCS; Hyclone). Fibroblasts were eliminated using immunoselection (Brockes et al. 1979), and the cells were cultured following $4 \mathrm{~d}$ in the medium containing 10 $\mu \mathrm{M}$ cytosine arabinoside (Sigma) to further decrease fibroblast proliferation. SCs were grown to $80 \%$ confluency, re-plated on poly-L-lysine-coated culture dishes, and maintained in normal growth medium (DMEM, 10\% FCS) with or without addition of PA $(100 \mu \mathrm{M})$ for $1 \mathrm{~h}$.

Rat primary culture Schwann cells were isolated from sciatic nerves of Sprague-Dawley rat pups shortly after birth (P3-P4). Fibroblasts were eliminated using immunoselection (Brockes et al. 1979). Purified SCs were cultured on poly-L-lysine-coated tissue plastic culture dishes in DMEM containing $10 \%$ fetal calf serum, $10 \mathrm{ng} / \mathrm{mL}$ neuregulin, and $4 \mu \mathrm{M}$ forskolin (Sigma) with

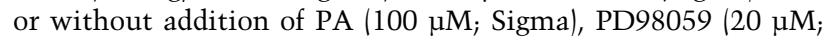
Cell Signaling), and propranolol (20 $\mu \mathrm{M}$; Sigma).

DRG explant cultures Dorsal root ganglia were dissected from embryonic day 16 (E16) rat embryos as previously described (Salzer and Bunge 1980). The ganglia were plated directly onto poly-L-lysine/laminine-coated glass slides and cultured in Neural Basal with B27 supplement for $24 \mathrm{~h}$. Next the medium was changed to C medium (DMEM with 10\% fetal bovine serum, 50 $\mathrm{ng} / \mathrm{mL}$ NGF [Harlan Bioproducts for Science], $2 \mathrm{mM}$ glutamine, and $11 \mathrm{mM}$ glucose). After $5 \mathrm{~d}$, myelination was induced by culturing the DRG explant cultures in C medium, supplemented with $50 \mu \mathrm{g} / \mathrm{mL}$ vitamin C (ascorbic acid [AA]; Sigma), and with or without different concentration of PA, U0126 (30

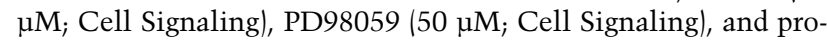
pranolol $(20 \mu \mathrm{M}$; Sigma). Explants were harvested after 3 or 4 wk. The number of myelinated segments was determined after staining with $\mathrm{Mpz}$ antibody. Only well-defined myelin segments were counted. The amount of $\mathrm{Mpz}$ expression was determined by Western blotting. 
Phosphatidic acid quantitation PA was quantified according to the previously described protocol (Saulnier-Blache et al. 2000). The endoneuriums from two nerves were homogenized in $1.5 \mathrm{~mL}$ of PBS containing $0.5 \mathrm{mM} \mathrm{Na}$ orthovanadate (Sigma) and extracted twice with 1 volume of butanol. After evaporation, phospholipids were solubilized in $1 \mathrm{~mL}$ of PBS containing $1 \%$ BSA and $0.5 \mathrm{mM} \mathrm{Na}$ orthovanadate. An aliquot of the solution was incubated for $90 \mathrm{~min}$ at $37^{\circ} \mathrm{C}$ in the presence or not of bovine pancreatic PLA2 $(3.8 \mathrm{U} / \mathrm{mL}$; Sigma). At the end of the incubation, phospholipids were extracted with butanol and dried, and LPA was quantified. The amount of PA corresponds to the amount of LPA detected after treatment with PLA2 after the subtraction of the amount of LPA detected without PLA2 treatment. The assay was performed in triplicate for each sample.

PAP activity measurement PAP activity was measured according to the previously described protocol (Han et al. 2006). Briefly, samples were disrupted using a Dounce homogenizer at $4^{\circ} \mathrm{C}$ in $50 \mathrm{mM}$ Tris- $\mathrm{HCl}$ (pH 7.5) buffer containing $0.25 \mathrm{M}$ sucrose, $10 \mathrm{mM} \beta$-mercaptoethanol, $1 \mathrm{mM}$ benzamidine, $0.5 \mathrm{mM}$ PMSF, and $5 \mathrm{mg} / \mathrm{mL}$ aprotinin, leupeptin, and pepstatin. The lysed cells were centrifuged at $1000 \mathrm{~g}$ for $10 \mathrm{~min}$ at $4^{\circ} \mathrm{C}$, and the supernatant was used as the cell extract. Total PAP activity $\left(\mathrm{Mg}^{2+}\right.$-dependent and $\mathrm{Mg}^{2+}$-independent) was measured for 20 $\mathrm{min}$ at $30^{\circ} \mathrm{C}$ in the reaction mixture (total volume of $100 \mu \mathrm{L}$ ) containing $50 \mathrm{mM}$ Tris- $\mathrm{HCl}(\mathrm{pH} 7.5), 1 \mathrm{mM} \mathrm{MgCl}_{2}, 10 \mathrm{mM}$ $\beta$-mercaptoethanol, $0.2 \mathrm{mM}$ PA, $2 \mathrm{mM}$ Triton X-100, and enzyme protein. The $\mathrm{Mg}^{2+}$-independent PA phosphatase activity was measured in the same reaction mixture except that $1 \mathrm{mM}$ EDTA was substituted for $1 \mathrm{mM} \mathrm{MgCl}_{2}$. The difference between the two enzyme activities was calculated as $\mathrm{Mg}^{2+}$-dependent PA phosphatase activity. The assay was performed in triplicate for each sample.

\section{Acknowledgments}

We thank Dr. Laura Feltri for providing us with $m P_{O} T O T A(C r e)$ mice; Dr. J.J. Archelos for a generous supply of anti-Mpz antibody; Jitka Fakan for assistance with electron microscopy; Dr. Thierry Kuntzer for his help with the measurement of nerve conduction velocity; Dr. Christian Bose, Patrick Burrola, and Joseph Hash for technical assistance; Drs. Carla Taveggia and James Salzer for their advice concerning DRG explants; Dr. Greg Lemke for helpful discussions and generous support in the initial phase of the project; and Dr. Jacqui Beckmann for his advice. This work was supported by grants from the Swiss $\mathrm{Na}$ tional Science Foundation (to R.C., grant PP00A-106714), from the Swiss foundation for fellowships in Medicine and Biology (to R.C., grant SSMBS1140), from the National Institutes of Health (to G.M.C., grant GM-28140), and from the European Union (to W.T.H. and M.H.G.V., grant EU-NEST 12702).

\section{References}

Alessi, D.R., Cuenda, A., Cohen, P., Dudley, D.T., and Saltiel, A.R. 1995. PD 098059 is a specific inhibitor of the activation of mitogen-activated protein kinase kinase in vitro and in vivo. J. Biol. Chem. 270: 27489-27494.

Andresen, B.T., Rizzo, M.A., Shome, K., and Romero, G. 2002. The role of phosphatidic acid in the regulation of the Ras/ MEK/Erk signaling cascade. FEBS Lett. 531: 65-68.

Boutry, J.M., Hauw, J.J., Gansmuller, A., Di-Bert, N., Pouchelet, M., and Baron-Van, E.A. 1992. Establishment and character- ization of a mouse Schwann cell line which produces myelin in vivo. J. Neurosci. Res. 32: 15-26.

Bozon, B., Kelly, A., Josselyn, S.A., Silva, A.J., Davis, S., and Laroche, S. 2003. MAPK, CREB and zif268 are all required for the consolidation of recognition memory. Philos. Trans. $R$. Soc. Lond. B Biol. Sci. 358: 805-814.

Brindley, D.N. 2004. Lipid phosphate phosphatases and related proteins: Signaling functions in development, cell division, and cancer. J. Cell. Biochem. 92: 900-912.

Brockes, J.P., Fields, K.L., and Raff, M.C. 1979. Studies on cultured rat Schwann cells. I. Establishment of purified populations from cultures of peripheral nerve. Brain Res. 165: $105-118$

Carman, G.M. and Han, G.-S. 2006. Roles of phosphatidate phosphatase enzymes in lipid metabolism. Trends Biochem. Sci. 31: 694-699.

Cavaletti, G., Miloso, M., Nicolini, G., Scuteri, A., and Tredici, G. 2007. Emerging role of mitogen-activated protein kinases in peripheral neuropathies. J. Peripher. Nerv. Syst. 12: 175194.

Coleman, R.A. and Lee, D.P. 2004. Enzymes of triacylglycerol synthesis and their regulation. Prog. Lipid Res. 43: 134176.

Croce, M.A., Eagon, J.C., LaRiviere, L.L., Korenblat, K.M., Klein, S., and Finck, B.N. 2007. Hepatic lipin $1 \beta$ expression is diminished in insulin-resistant obese subjects and is reactivated by marked weight loss. Diabetes 56: 2395-2399.

de Preux, A.S., Goosen, K., Zhang, W., Sima, A.A., Shimano, H., Ouwens, D.M., Diamant, M., Hillebrands, J.L., Rozing, J., Lemke, G., et al. 2007. SREBP-1c expression in Schwann cells is affected by diabetes and nutritional status. Mol. Cell. Neurosci. 35: 525-534.

Desbarats, J., Birge, R.B., Mimouni-Rongy, M., Weinstein, D.E., Palerme, J.S., and Newell, M.K. 2003. Fas engagement induces neurite growth through ERK activation and p35 upregulation. Nat. Cell Biol. 5: 118-125.

Donkor, J., Sariahmetoglu, M., Dewald, J., Brindley, D.N., and Reue, K. 2007. Three mammalian lipins act as phosphatidate phosphatases with distinct tissue expression patterns. $J$. Biol. Chem. 282: 3450-3457.

Dupree, J.L., Girault, J.A., and Popko, B. 1999. Axo-glial interactions regulate the localization of axonal paranodal proteins. J. Cell Biol. 147: 1145-1152.

Dyck, P.J. and Thomas, P.K. 2005. Peripheral neuropathy, 4th ed. Elsevier Saunders, Philadelphia, PA.

Eichberg, J. and Zhu, X. 1992. Diacylglycerol composition and metabolism in peripheral nerve. Adv. Exp. Med. Biol. 318: 413-425.

Eldridge, C.F., Bunge, M.B., Bunge, R.P., and Wood, P.M. 1987. Differentiation of axon-related Schwann cells in vitro. I. Ascorbic acid regulates basal lamina assembly and myelin formation. J. Cell Biol. 105: 1023-1034.

Feltri, M.L., D'Antonio, M., Previtali, S., Fasolini, M., Messing, A., and Wrabetz, L. 1999. P0-Cre transgenic mice for inactivation of adhesion molecules in Schwann cells. Ann. N. Y. Acad. Sci. 883: 116-123.

Finck, B.N., Gropler, M.C., Chen, Z., Leone, T.C., Croce, M.A., Harris, T.E., Lawrence Jr., J.C., and Kelly, D.P. 2006. Lipin 1 is an inducible amplifier of the hepatic PGC-1 $\alpha /$ PPAR $\alpha$ regulatory pathway. Cell Metab. 4: 199-210.

Garbay, B., Heape, A.M., Sargueil, F., and Cassagne, C. 2000 Myelin synthesis in the peripheral nervous system. Prog. Neurobiol. 61: 267-304.

Han, G.-S., Wu, W.I., and Carman, G.M. 2006. The Saccharomyces cerevisiae Lipin homolog is a $\mathrm{Mg}^{2+}$-dependent phosphatidate phosphatase enzyme. J. Biol. Chem. 281: 9210- 
9218.

Harris, T.E., Huffman, T.A., Chi, A., Shabanowitz, J., Hunt, D.F., Kumar, A., and Lawrence Jr., J.C. 2007. Insulin controls subcellular localization and multisite phosphorylation of the phosphatidic acid phosphatase, lipin 1. J. Biol. Chem. 282: $277-286$.

Harrisingh, M.C., Perez-Nadales, E., Parkinson, D.B., Malcolm, D.S., Mudge, A.W., and Lloyd, A.C. 2004. The Ras/Raf/ERK signalling pathway drives Schwann cell dedifferentiation. EMBO J. 23: 3061-3071.

Huffman, T.A., Mothe-Satney, I., and Lawrence Jr., J.C. 2002. Insulin-stimulated phosphorylation of lipin mediated by the mammalian target of rapamycin. Proc. Natl. Acad. Sci. 99: 1047-1052.

Jurevics, H.A. and Morell, P. 1994. Sources of cholesterol for kidney and nerve during development. J. Lipid Res. 35: 112120.

Keswani, S.C., Pardo, C.A., Cherry, C.L., Hoke, A., and McArthur, J.C. 2002. HIV-associated sensory neuropathies. AIDS 16: 2105-2117.

Langner, C.A., Birkenmeier, E.H., Roth, K.A., Bronson, R.T., and Gordon, J.I. 1991. Characterization of the peripheral neuropathy in neonatal and adult mice that are homozygous for the fatty liver dystrophy (fld) mutation. J. Biol. Chem. 266: 11955-11964.

Lindegaard, B., Larsen, L.F., Hansen, A.B., Gerstoft, J., Pedersen, B.K., and Reue, K. 2007. Adipose tissue lipin expression levels distinguish HIV patients with and without lipodystrophy. Int. J. Obes. (Lond) 31: 449-456.

Liu, P., Jenkins, N.A., and Copeland, N.G. 2003. A highly efficient recombineering-based method for generating conditional knockout mutations. Genome Res. 13: 476-484.

Marcus, J. and Popko, B. 2002. Galactolipids are molecular determinants of myelin development and axo-glial organization. Biochim. Biophys. Acta 1573: 406-413.

Morell, P. and Jurevics, H. 1996. Origin of cholesterol in myelin. Neurochem. Res. 21: 463-470.

Ogata, T., Iijima, S., Hoshikawa, S., Miura, T., Yamamoto, S., Oda, H., Nakamura, K., and Tanaka, S. 2004. Opposing extracellular signal-regulated kinase and Akt pathways control Schwann cell myelination. J. Neurosci. 24: 6724-6732.

O'Hara, L., Han, G.S., Peak-Chew, S., Grimsey, N., Carman, G.M., and Siniossoglou, S. 2006. Control of phospholipid synthesis by phosphorylation of the yeast lipin Pahlp/ Smp2p $\mathrm{Mg}^{2+}$-dependent phosphatidate phosphatase. I. Biol. Chem. 281: 34537-34548.

Peterfy, M., Phan, J., Xu, P., and Reue, K. 2001. Lipodystrophy in the fld mouse results from mutation of a new gene encoding a nuclear protein, lipin. Nat. Genet. 27: 121-124.

Peterfy, M., Phan, J., and Reue, K. 2005. Alternatively spliced lipin isoforms exhibit distinct expression pattern, subcellular localization, and role in adipogenesis. J. Biol. Chem. 280: 32883-32889.

Phan, J. and Reue, K. 2005. Lipin, a lipodystrophy and obesity gene. Cell Metab. 1: 73-83.

Rizzo, M.A., Shome, K., Vasudevan, C., Stolz, D.B., Sung, T.C., Frohman, M.A., Watkins, S.C., and Romero, G. 1999. Phospholipase D and its product, phosphatidic acid, mediate agonist-dependent raf- 1 translocation to the plasma membrane and the activation of the mitogen-activated protein kinase pathway. J. Biol. Chem. 274: 1131-1139.

Saher, G., Brugger, B., Lappe-Siefke, C., Mobius, W., Tozawa, R., Wehr, M.C., Wieland, F., Ishibashi, S., and Nave, K.A. 2005. High cholesterol level is essential for myelin membrane growth. Nat. Neurosci. 8: 468-475.

Salzer, J.L. and Bunge, R.P. 1980. Studies of Schwann cell pro- liferation. I. An analysis in tissue culture of proliferation during development, Wallerian degeneration, and direct injury. J. Cell Biol. 84: 739-752.

Saulnier-Blache, J.S., Girard, A., Simon, M.F., Lafontan, M., and Valet, P. 2000. A simple and highly sensitive radioenzymatic assay for lysophosphatidic acid quantification. J. Lipid Res. 41: 1947-1951.

Sciorra, V.A. and Morris, A.J. 2002. Roles for lipid phosphate phosphatases in regulation of cellular signaling. Biochim. Biophys. Acta 1582: 45-51.

Sheu, J.Y., Kulhanek, D.J., and Eckenstein, F.P. 2000. Differential patterns of ERK and STAT3 phosphorylation after sciatic nerve transection in the rat. Exp. Neurol. 166: 392-402.

Sima, A.A. 2003. New insights into the metabolic and molecular basis for diabetic neuropathy. Cell. Mol. Life Sci. 60: 2445-2464.

Tapinos, N., Ohnishi, M., and Rambukkana, A. 2006. ErbB2 receptor tyrosine kinase signaling mediates early demyelination induced by leprosy bacilli. Nat. Med. 12: 961-966.

Topilko, P., Levi, G., Merlo, G., Mantero, S., Desmarquet, C., Mancardi, G., and Charnay, P. 1997. Differential regulation of the zinc finger genes Krox-20 and Krox-24 (Egr-1) suggests antagonistic roles in Schwann cells. J. Neurosci. Res. 50: 702-712.

Verheijen, M.H., Chrast, R., Burrola, P., and Lemke, G. 2003. Local regulation of fat metabolism in peripheral nerves. Genes \& Dev. 17: 2450-2464.

Wang, X., Devaiah, S.P., Zhang, W., and Welti, R. 2006. Signaling functions of phosphatidic acid. Prog. Lipid Res. 45: 250278.

Weiner, J.A. and Chun, J. 1999. Schwann cell survival mediated by the signaling phospholipid lysophosphatidic acid. Proc. Nat1. Acad. Sci. 96: 5233-5238.

Weiner, J.A., Fukushima, N., Contos, J.J., Scherer, S.S., and Chun, J. 2001. Regulation of Schwann cell morphology and adhesion by receptor-mediated lysophosphatidic acid signaling. J. Neurosci. 21: 7069-7078.

Weinmaster, G. and Lemke, G. 1990. Cell-specific cyclic AMPmediated induction of the PDGF receptor. EMBO I. 9: 915920.

Yao, J.K. 1985. Metabolic turnover of fatty acids and acylglycerols in rat sciatic nerve. J. Neurochem. 45: 589-595.

Yao-Borengasser, A., Rasouli, N., Varma, V., Miles, L.M., Phanavanh, B., Starks, T.N., Phan, J., Spencer III, H.J., McGehee Jr., R.E., Reue, K., et al. 2006. Lipin expression is attenuated in adipose tissue of insulin-resistant human subjects and increases with peroxisome proliferator-activated receptor $\gamma$ activation. Diabetes 55: 2811-2818.

Zorick, T.S., Syroid, D.E., Arroyo, E., Scherer, S.S., and Lemke, G. 1996. The transcription factors SCIP and Krox-20 mark distinct stages and cell fates in Schwann cell differentiation. Mol. Cell. Neurosci. 8: 129-145. 


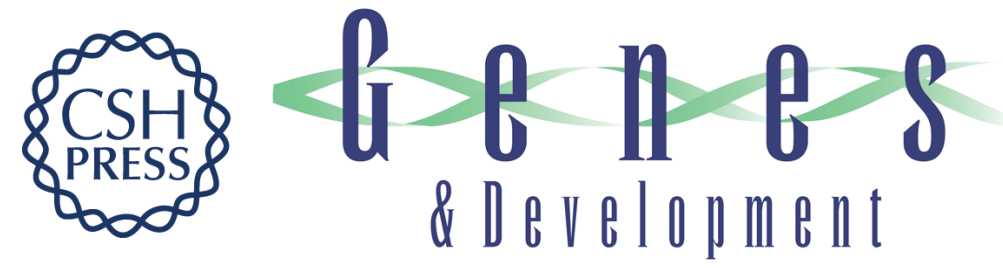

\section{Phosphatidic acid mediates demyelination in Lpin1 mutant mice}

Karim Nadra, Anne-Sophie de Preux Charles, Jean-Jacques Médard, et al.

Genes Dev. 2008, 22:

Access the most recent version at doi:10.1101/gad.1638008

Supplemental

Material

References

This article cites 52 articles, 20 of which can be accessed free at:

http://genesdev.cshlp.org/content/22/12/1647.full.html\#ref-list-1

\section{License}

Email Alerting Service

http://genesdev.cshlp.org/content/suppl/2008/06/11/22.12.1647.DC1 right corner of the article or click here.

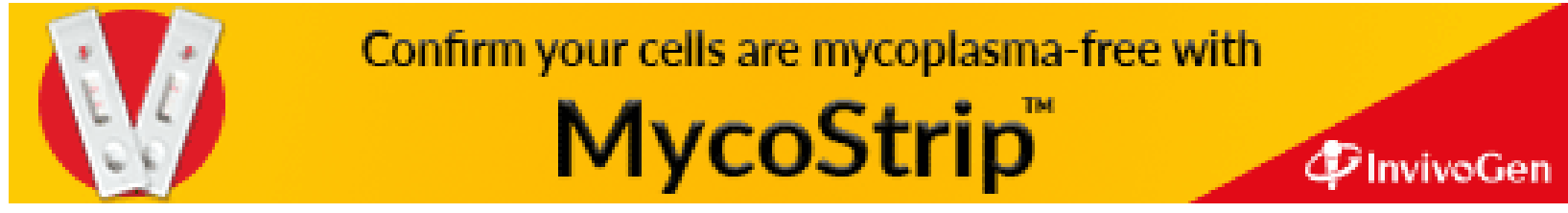

